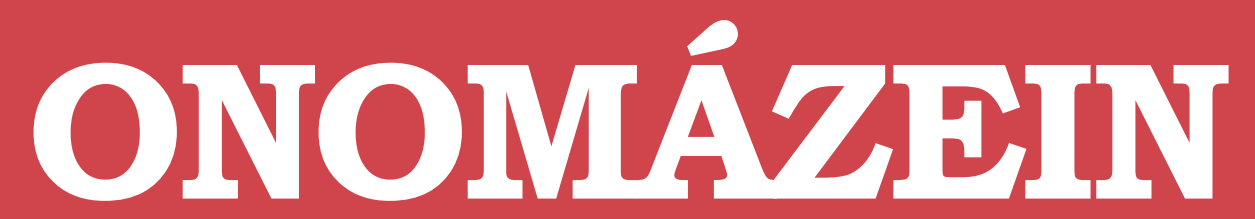

Revista de lingüística, filología y traducción
PONTIFICIA UNIVERSIDAD CATÓLICA DE CHILE FACULTAD DE LETRAS

\title{
Lenguas indígenas en la legislación de los países hispanoamericanos
}

Indigenous languages in the Legislation of Hispano-American nations

\section{Lenka Zajícová}

Universidad Palacký de Olomouc

Chequia

Número especial

Las lenguas amerindias en Iberoamérica: retos para el siglo XXI

2017
ONOMÁZEIN - Número especial

Las lenguas amerindias en Iberoamérica: retos para el siglo XXI (2017): 171-203 DOI: 10.7764/onomazein.amerindias.10

\section{(c) $\odot$}

Lenka Zajícová: Departamento de Lenguas Románicas, Facultad de Filosofía, Universidad Palacký de Olomouc, Chequia. | Correo electrónico: lenka.zajicova@upol.cz

Fecha de recepción: noviembre de 2016

Fecha de aceptación: marzo de 2017 


\section{Resumen}

En las últimas décadas, en la mayoría de los países hispanoamericanos se da un proceso similar: una mayor promoción de las lenguas indígenas a nivel educacional, social y legal, hasta su proclamación, en algunos casos, como lenguas cooficiales. A pesar de puntos de partida comunes, los resultados actuales son muy diferentes si comparamos el estatus constitucional de estas lenguas y las leyes lingüísticas vigentes, que van desde meras proclamaciones simbólicas hasta propuestas muy ambiciosas. El artículo presenta la evolución y la situación actual de la legislación que declara la cooficialidad de las lenguas indígenas en los países hispanoamericanos, y la compara tanto desde el punto de vista cualitativo, presentando su clasificación, como desde el cronológico.

Palabras clave: lenguas indígenas; legislación lingüística; Hispanoamérica; políticas lingüísticas.

\section{Abstract}

In recent decades, in most Latin American countries a similar process occurs: the promotion of indigenous languages to an educational, social and legal level, including, in some cases, their status as co-official languages. Despite some common starting points, the current situation is very different in the different countries if we compare the constitutional acknowledgement of these indigenous languages and the present language legislation, ranging from mere symbolic proclamations to very ambitious proposals. The article presents the evolution and the indigenous languages policies and regulation in Latin American countries, from a qualitative and comparative point of view, presenting their classification, as well as chronology.

Keywords: indigenous languages; linguistic legislation; Hispanic America; language policies. 


\section{Introducción}

El presente artículo trata de la evolución y el estado actual de la legislación lingüística en los países hispanoamericanos, en especial la que declara como idiomas oficiales las lenguas indígenas ${ }^{1}$. En este sentido, no pretendemos evaluar el cumplimiento de esta legislación, ya que sería otro tema, que, además, sobrepasaría por mucho el espacio del que disponemos.

En la parte inicial, vamos a presentar una comparación de la situación legislativa de los países hispanoamericanos en la materia de idioma(s) oficial(es); después, haremos una comparación de los países en relación con el tema de la oficialidad de las lenguas indígenas; al final, presentaremos brevemente la evolución y la situación actual en cada uno de los países hispanoamericanos².

El proceso de emancipación legislativa de las lenguas indígenas que, en las últimas décadas, se da en casi todos los países hispanoamericanos parece guardar bastantes similitudes, pero una mirada más cercana revela diferencias importantes, tanto en su datación y evolución como en los resultados actuales. Merece la pena mencionar que en muchos países el proceso de reconocimiento oficial de las lenguas indígenas se desarrolla en el contexto dado por el Convenio 169 de 1989 sobre pueblos indígenas y tribales en países independientes de la Organización Internacional del Trabajo (OIT, 1989), el cual, entre todos los tratados internacionales, posee actualmente la mayor capacidad de influencia en esta materia. Este convenio fue firmado y ratificado por la mayoría de los países hispanoamericanos, y varios documentos legislativos a los que se aludirá a continuación se refieren explícitamente a él. No obstante, también hay países donde el reconocimiento oficial de las lenguas indígenas se dio mucho antes de la ratificación de este convenio, como es el caso de Perú (la primera oficialización del quechua fue en 1975, mientras que el Convenio 169 fue ratificado en 1994) o Nicaragua (la oficialización de lenguas indígenas se dio a partir de 1987 y el Convenio 169 fue ratificado en 2010)3.

$1 \quad$ No es nuestra intención entrar en la discusión terminológica de cómo denominarlas. Elegimos este término por ser el más difundido en la legislación estudiada y generalmente comprensible. De hecho, la misma legislación varía mucho de un país a otro y en el curso del tiempo: lenguas indígenas (Argentina, Bolivia, Chile, Costa Rica, Ecuador, México, Panamá, Paraguay), idiomas indígenas (Chile, Venezuela), lenguas aborígenes (Ecuador, Perú), lenguas vernáculas (Honduras, Guatemala), lenguas originarias (Perú), lenguas nativas (Colombia), lenguas autóctonas (El Salvador), idiomas ancestrales (Ecuador), lenguas de los Pueblos Indigenas supervivientes / idiomas de los Pueblos Originarios / lenguas de los Pueblos Preexistentes (Argentina), idiomas de las naciones y pueblos indígena originario campesinos (Bolivia), lenguas de las comunidades de la Costa Atlántica (Nicaragua).

2 La tabla del final recoge toda la legislación que establece la oficialidad de las lenguas indígenas en Hispanoamérica por orden cronológico.

3 Entre otras fuentes importantes de declaración de derechos indígenas cabe menciona las actividades patrocinadas por la UNESCO, como la Declaración Universal de Derechos Lingüísticos, proclamada en Barcelona en 1996, o la proclamación del 21 de febrero el Día Internacional de la Lengua Materna a partir del 2000. 


\section{La situación legislativa de los países en cuanto a la oficialidad de las len- guas indígenas}

Si se desea estudiar la oficialidad de lenguas indígenas en los países hispanoamericanos, lo primero que hay que tener en cuenta es el hecho de que no todos los países a nivel nacional tienen declarado de iure el idioma oficial. Si bien este es el caso de la mayoría de ellos, suponen una excepción México, Argentina, Chile y Uruguay. Este hecho tiene, por supuesto, ciertas repercusiones a la hora de establecer el estatus legislativo de las lenguas indígenas.

En cuanto a los países con idioma(s) oficial(es) declarado(s), en todos salvo Puerto Rico4, la declaración aparece en sus constituciones, si bien en algunos casos la oficialidad empezó siendo declarada por una ley de rango inferior y solo después encontró el camino a la constitucionalidad, como en Bolivia (Decreto Supremo, 2000; Constitución, 2009) y Perú (Decreto Ley, 1975; Constitución, 1979) o, los casos más extremos en cuanto a la distancia temporal, Honduras (Acuerdo Presidencial 1882, Constitución 1957) y la República Dominicana (Ley 1912, Constitución 2010). Algunos países tienen además otras leyes posteriores a sus constituciones que explicitan la oficialidad de las lenguas y especifican su estatus, como es el caso de Bolivia, Colombia, El Salvador, Guatemala, Nicaragua, Paraguay, Perú y Venezuela.

Según el criterio de la oficialidad de las lenguas indígenas, podemos dividir los países hispanoamericanos en dos mitades casi perfectas: en diez países existe alguna legislación al respecto, en concreto: en Argentina, Bolivia, Chile, Colombia, Ecuador, México, Nicaragua, Paraguay, Perú y Venezuela; en otros nueve, no existe, es decir: en Costa Rica, Cuba, El Salvador, Guatemala, Honduras, Panamá, Puerto Rico, República Dominicana y Uruguay. Esta división básica necesita, sin embargo, bastante matización, que procuramos ofrecer a continuación.

\subsection{Países sin lenguas indígenas como lenguas oficiales}

En este grupo tenemos, por un lado, países cuya situación lingüística no ha requerido ninguna legislación al respecto, ya que las lenguas indígenas desaparecieron hace mucho, como es el caso de Cuba, la República Dominicana, Uruguay o Puerto Rico, que, por su parte, supone un caso especial, ya que tiene dos idiomas oficiales, el castellano y el inglés (Ley 1/1993, art. 1).

En los otros cinco países, el reconocimiento legal de las lenguas indígenas alcanza diferentes grados. El menor grado está representado por Honduras, en cuya Constitución no hay ninguna mención de ellas, y solo las reconoce en la legislación que rige la educación bilingüe (Honduras, 1994, 2011).

4 En Puerto Rico existe una legislación especial, tal y como se verá seguidamente (Puerto Rico, 1993). 
Una situación diferente se da en El Salvador y Costa Rica, en cuyas constituciones se declara el compromiso del estado de preservar, difundir y respetar las lenguas autóctonas (El Salvador, 1983: art. 62) y de mantener y cultivar las lenguas indígenas nacionales (Costa Rica, 1949: art. 76, reformado en 1999).

En los dos países restantes se da un reconocimiento legal explícito a las lenguas indígenas, pero sin haberlas declarado explícitamente idiomas oficiales, estatus este reservado para el castellano: la ley lingüística de Panamá declara que "se reconocen las lenguas de los pueblos indígenas" (Panamá, 2010: art. 1), sin haber explicitado con qué estatus se reconocen. El máximo grado de reconocimiento legal en este grupo está representado por Guatemala, cuyas lenguas indígenas son declaradas en su ley lingüística idiomas nacionales (Guatemala, 2003: art. 1)5.

\subsection{Países con lenguas indígenas oficiales}

El segundo grupo está comprendido por los países que otorgan el papel de idioma oficial a nivel nacional al castellano, pero al mismo tiempo establecen una oficialidad limitada de otras lenguas, principalmente las indígenas. De nuevo, es posible identificar bastantes diferencias, dadas tanto por el tipo de legislación que declara la oficialidad de lenguas indígenas como por el tipo y alcance de su limitación.

\subsubsection{Oficialidad declarada a nivel provincial o municipal}

En este grupo se encuentran los países sin idioma oficial nacional de iure y con el castellano como idioma oficial de facto, pero con otros idiomas cooficiales declarados en un nivel de legislación inferior, provincial o municipal; es el caso de Argentina y Chile. En Argentina existe la declaración de idiomas oficiales en dos de sus 23 provincias; en Chile esto afecta solo a dos comunas, así que la situación legislativa de estos países en este aspecto se acerca mucho a la de Uruguay, mencionada en el primer grupo.

\subsubsection{Oficialidad declarada a nivel nacional}

En estos países se establece la oficialidad de dos o más lenguas a nivel de la legislación nacional, pero se trata de una oficialidad jerarquizada, ya que se declara un idioma oficial, el

5 El primer país que a nivel constitucional declara una lengua de origen amerindio como idioma nacional es Paraguay y la lengua es, por supuesto, el guaraní (Paraguay, 1967: art. 5). 
castellano o español, a nivel nacional, y otro(s) oficiales solo en parte. Esta limitación es, mayoritariamente, de tipo territorial, pero es necesario indicar los diferentes casos.

En Nicaragua, la limitación territorial se concreta en la Constitución misma ("Costa Atlántica”, a partir de 2014 "Costa Caribe"), que declara el uso oficial de lenguas indígenas en las Regiones Autónomas de la zona (Nicaragua, 1987a,b: art. 11; 1987c: art. 5). En los demás países, la limitación territorial del uso oficial no se da identificando un territorio concreto en la ley, sino que se expresa condicionada a la presencia de las comunidades indígenas. La delimitación más general es la de la Constitución colombiana: "Las lenguas y dialectos de los grupos étnicos son también oficiales en sus territorios” (Colombia, 1991: art. 10)6.

Una situación algo parecida es la de Ecuador, en cuya Constitución declara que los "idiomas ancestrales son de uso oficial para los pueblos indígenas en las zonas donde habitan", con la gran diferencia de que en este país se distinguen tres niveles de oficialidad, siendo el castellano, el kichwa y el shuar "idiomas oficiales de relación intercultural" (sin limitación territorial) y "el castellano es el idioma oficial del Ecuador" (Ecuador, 2008: art. 2).

Perú declara en su Constitución el quechua, el aimara y las demás lenguas aborígenes como idiomas oficiales “en las zonas donde predominen” (Perú, 1993: art. 48), especificándolo en su ley lingüística de la siguiente manera: "en los distritos, provincias o regiones en donde predominen" (Perú, 2011: art. 9).

El alcance potencial más amplio es el declarado para las lenguas indígenas de Bolivia, ya que el primer parágrafo del artículo constitucional en cuestión establece una oficialidad del mismo nivel para todas las lenguas (solo que el castellano se menciona en primer lugar): "Son idiomas oficiales del Estado el castellano y todos los idiomas de las naciones y pueblos indígena originario campesinos", enumerándose 36 idiomas indígenas (Bolivia, 2009: art. 5, par. 1). Sin embargo, el segundo parágrafo lo precisa y establece una jerarquía: los gobiernos de todos los niveles deben escoger, aparte del castellano, que es el idioma

6 La ley lingüística de Colombia (1381/2010) trata la localización del uso de lenguas nativas de manera más detallada, pero ya no menciona explícitamente su oficialidad: "Los hablantes de lengua nativa tendrán derecho a comunicarse entre sí en sus lenguas, sin restricciones en el ámbito público o privado, en todo el territorio nacional, en forma oral o escrita, en todas sus actividades sociales, económicas, políticas, culturales y religiosas, entre otras. Todos los habitantes de los territorios de los pueblos indígenas, del corregimiento de San Basilio de Palenque (municipio de Mahates, departamento de Bolívar), y del departamento de San Andrés y Providencia, tendrán el derecho a conocer y a usar las lenguas nativas de uso tradicional en estos territorios, junto con el castellano. A las comunidades del pueblo Rom, se les garantizará el derecho a usar el castellano y la lengua Romaní de uso tradicional en dichas comunidades" (Colombia, 2010: art. 5). 
oficial obligatorio, por lo menos un idioma oficial más, "tomando en cuenta el uso, la conveniencia, las circunstancias, las necesidades y preferencias de la población en su totalidad o del territorio en cuestión" (Bolivia, 2009: art. 5, par. 2), lo que supone una limitación de tipo básicamente territorial.

Pertenece al mismo tipo también México, si bien se trata de un caso peculiar, ya que no tiene declarado de iure ningún idioma oficial, pero tanto las lenguas indígenas como el español se reconocen como lenguas nacionales, que "tienen la misma validez en su territorio, localización y contexto en que se hablen” (México, 2003: art. 4). Otra vez se trata de una limitación básicamente territorial, ya que se supone que el español se extiende por todo el país, mientras que las lenguas indígenas tienen sus territorios más limitados.

Otro tipo de limitación es el representado por Venezuela, que declara el uso oficial de los idiomas indígenas "para los pueblos indígenas", es decir, en función de las comunidades de hablantes, y explicita que "deben ser respetados en todo el territorio de la República" (Venezuela, 1999: art. 9).

Un caso especial es el de Paraguay, donde las dos lenguas oficiales, el castellano y el guaraní, tienen el mismo estatus en la Constitución, pero se ponen ciertos límites al uso del guaraní en la Ley de Lenguas (Paraguay, 2010). Estos no son territoriales, sino contextuales; por ejemplo, se declara explícitamente que las leyes se promulgarán en castellano. Por otra parte, hay que señalar que las demás lenguas indígenas en Paraguay solo son declaradas parte del patrimonio cultural, así que su situación jurídica se acerca más bien a la de las lenguas indígenas en Costa Rica o El Salvador.

\section{Situación legislativa de las lenguas por países 3.1. Argentina}

Argentina es uno de los países sin lengua oficial declarada de iure ni por la Constitución Nacional ni por una ley o decreto de alcance nacional?. El español, idioma oficial de facto, suele

7 El único texto referido a un tema lingüístico en la Constitución argentina es el de las competencias del Congreso en relación con la educación bilingüe: "Corresponde al Congreso: [...] 17. Reconocer la preexistencia étnica y cultural de los pueblos indígenas argentinos. Garantizar el respeto a su identidad y el derecho a una educación bilingüe e intercultural; [...]" (Argentina, 1994: art. 75). En este texto no prestamos una especial atención a la legislación que dicta normas sobre la presencia de las lenguas indígenas en los sistemas educativos, salvo casos excepcionales, sobre todo cuando no existe otra legislación lingüística o cuando en estas leyes se menciona explícitamente la oficialidad. 
denominarse idioma nacional, pero en algunos contextos oficiales o semioficiales podemos encontrarnos incluso con la denominación idioma oficial².

Dos de las 23 provincias argentinas, Corrientes y Chaco, han establecido en la primera década de este siglo otras lenguas oficiales en su legislación provincial. En concreto, se trata del guaraní en la provincia de Corrientes, que se declara "idioma oficial alternativo" (Argentina, 2004: art. 1), sin haberse explicitado con qué idioma alterna, aunque se trata, obviamente, del español; y de las lenguas qom, moqoit y wichí en la provincia del Chaco, que son declaradas "lenguas oficiales de la Provincia, además del Castellano-Español” (Argentina, 2010: art. 1)9.

\subsection{Bolivia}

Como ya se ha expuesto anteriormente, el potencial de cooficialidad, declarado para los idiomas indígenas de Bolivia, es el más alto de todos los países hispanoamericanos. La Constitución declara como idiomas oficiales el castellano ${ }^{10}$ y otros 36 idiomas de las naciones y pueblos indígenas originarios campesinos (Bolivia, 2009: art. 5, par. 1). Los gobiernos de todos los niveles (plurinacional, departamentales, autónomos municipales) deben usar, al menos, dos idiomas oficiales (incluido el castellano). Eso significa que, por lo menos, uno de los idiomas indígenas, el escogido por el gobierno central, debería tener el mismo alcance que el castellano, es decir, en todo el país, al menos en cuanto a los asuntos del gobierno.

Los detalles del uso oficial de las lenguas han sido especificados posteriormente en la Ley General de Derechos y Políticas Lingüísticas (Bolivia, 2012) ${ }^{11}$. En esta ley se encuentra una de las mayores exigencias a los empleados públicos de todos los países hispanoamericanos, ya que la tercera de sus disposiciones transitorias, que reglamenta el art. 234 de la Constitución ("Para acceder al desempeño de funciones públicas se requiere: [...] 7. Hablar al menos dos

8 Por ejemplo, en la Ley de Medios aparece la siguiente normativa: "La programación que se emita a través de los servicios contemplados por esta ley, incluyendo los avisos publicitarios y los avances de programas, debe estar expresada en el idioma oficial o en los idiomas de los Pueblos Originarios [...]" (Argentina, 2009: art. 9). O, en el portal oficial del Estado, se puede encontrar la siguiente información: "Nuestra lengua oficial es el español..." (Argentina, Ministerio de Modernización de la Nación, Dirección Nacional de Servicios Digitales, Argentina.gob.ar [https://www.argentina.gob. ar/pais, fecha de consulta: 1 de noviembre de 2016]).

9 Esta ley fue precedida por la oficialización de los tres idiomas mencionados por un decreto provincial (Argentina, 2008).

10 Al referirnos a esta lengua, respetamos la denominación que recibe en la legislación del estado respectivo.

11 En cuanto al papel de las lenguas oficiales en la educación, lo reglamenta la Ley de la Educación "Avelino Siñani - Elizardo Pérez" (Bolivia, 2010: art. 7). 
idiomas oficiales del país" [Bolivia, 2009: art. 234]), reza: "toda servidora o servidor público que no hable un idioma de las naciones y pueblos indígena originario campesinos, deberá aprender el idioma de la región a nivel comunicativo, de acuerdo al principio de territorialidad, en un plazo máximo de tres (3) años" (Bolivia, 2012: disp. trans. 3).

\subsection{Chile}

A nivel nacional, Chile no tiene ningún idioma oficial establecido, ni por la Constitución (comp. Chile, 1980) ni por otro documento legislativo, siendo el idioma oficial de facto el castellano. Tampoco hay una ley específica que trate el tema de los idiomas indígenas, aunque existe un proyecto de Ley general de derechos lingüísticos de los pueblos indígenas de Chile, cuyo texto se inspira, principalmente, en la Ley General de Derechos Lingüísticos de los Pueblos Indigenas mexicana de 2003, y que ingresó al Congreso en 2014 y desde entonces está en tramitación en sus dos cámaras ${ }^{12}$. Dado que Chile no tiene ningún idioma oficial declarado de iure, el proyecto de ley tampoco propone este estatus para las lenguas indígenas, sino que las reconoce, junto con el castellano, como lenguas nacionales y declara que "tendrán la misma validez jurídica, institucional, social, pública en sus territorios, comunidades y contexto en que se hablen" (Chile, 2014a,b: art. 7).

La situación de las lenguas indígenas está actualmente considerada en el artículo 28 de la llamada Ley Indígena: "El reconocimiento, respeto y protección de las culturas e idiomas indígenas contemplará: a) El uso y conservación de los idiomas indígenas, junto al español en las áreas de alta densidad indígena [...]" (Chile, 1993: art. 28). En el artículo 54 se dicta, además, que "el Juez encargado del conocimiento de una causa indígena, a solicitud de parte interesada y en actuaciones o diligencias en que se requiera la presencia personal del indígena, deberá aceptar el uso de la lengua materna [...]" (Chile, 1993: art. 54). Al papel de las lenguas indígenas en la educación básica chilena está dedicado el Decreto 280/2009 del Ministerio de Educación (Chile, 2009).

A nivel de legislación municipal y regional, también hay iniciativas de oficialización de las lenguas indígenas, en concreto en la región de La Araucanía. El mapuche (mapudungun) fue, de hecho, declarado lengua cooficial de las comunas de Galvarino (en agosto de 2013) y Padre Las Casas (en

12 El 20 de mayo de 2014, el proyecto fue ingresado al Senado (Senado de la República de Chile, Boletín, n. ${ }^{9} 936304$ [http://www.senado.cl/appsenado/templates/tramitacion/index.php\#, fecha de consulta: 29 de octubre de 2016]), y el I de julio de 2014 fue ingresado en versión casi idéntica bajo el nombre "Ley General de Derechos Lingüísticos de los Pueblos Originarios de Chile" a la Cámara de Diputados (Cámara de Diputados de Chile, Boletín, n. 9424-17, https://www.camara.cl/pley/ pley_detalle.aspx?prmID=9838\&prmBoletin=9424-17, fecha de consulta: 29 de octubre de 2016]). En la actualidad, las dos versiones están en la etapa del "primer trámite constitucional", la última actividad se dio el 1 y el 3 de marzo de 2016, respectivamente. 
octubre de 2014) por ordenanzas municipales ${ }^{13}$. En marzo de 2015 el Consejo Regional de La Araucanía también votó a favor de su oficializaciónㄹ, pero aún no hay respuesta del Gobierno Regional.

\subsection{Colombia}

Colombia es uno de los países que declaran la oficialidad de las lenguas indígenas limitada territorialmente en la Constitución: "El castellano es el idioma oficial de Colombia. Las Ienguas y dialectos de los grupos étnicos son también oficiales en sus territorios" (Colombia, 1991: art. 10). Colombia tiene una ley lingüística especial (Ley 1381/2010), que dicta "normas sobre reconocimiento, fomento, protección, uso, preservación y fortalecimiento de las lenguas de los grupos étnicos de Colombia y sobre sus derechos lingüísticos y los de sus hablantes", como reza su título, pero que explícitamente no menciona la oficialidad de las lenguas nativas (como se denominan en esta ley), salvo en el caso del reconocimiento oficial de los antropónimos y topónimos (Colombia, 2010: art. 6).

\subsection{Costa Rica}

Costa Rica reconoce en su Constitución un único idioma oficial, el español, a partir del año 1975 (Costa Rica, 1949: art. 76, reformado en 1975). Este artículo fue reformado en 1999, y se añadió la siguiente declaración: "No obstante, el Estado velará por el mantenimiento y cultivo de las lenguas indígenas nacionales”. Costa Rica carece de una ley específica en materia lingüística.

\subsection{Cuba}

Cuba tiene declarado el español como único idioma oficial desde la Constitución de 1940 (Cuba, 1940: art. 6), lo que fue confirmado por las siguientes Constituciones de 1959 (Cuba,

13 "Galvarino es la primera comuna de Chile en establecer dos idiomas oficiales: el mapudungún y el español", 07/08/2013, en Municipalidad de Galvarino [http://www.galvarinochile.cl/webv2/?p=9806, fecha de consulta: 1 de noviembre de 2016]; Patricia Acuña, "Declaran oficialmente el mapudungún como segunda lengua en Padre Las Casas", 21/10/2014, en BioBioChile [http://www.biobiochile. cl/2014/10/21/declaran-oficialmente-el-mapudungun-como-segunda-lengua-en-padre-las-casas. shtml, fecha de consulta: 1 de noviembre de 2016].

14 "Se acuerda por unanimidad de los consejeros presentes, pronunciarse favorablemente para respaldar la oficialización de la lengua mapudungun de la Región de La Araucanía” (Consejo Regional del Gobierno Regional de La Araucanía, Acta Sesión Ordinaria, n. ${ }^{\circ}$ 26, 18/03/2015, pág. 8 [http://www. gorearaucania.cl/index.php?id=311\&no_cache=1, fecha de consulta: 1 de noviembre de 2016]). 
1959: art. 6) y de 1976, que es la última y cuyas reformas de 1992 y 2002 no afectaron el texto del artículo en cuestión (Cuba, 1976: art. 2).

\subsection{Ecuador}

Ecuador es el país con la evolución más compleja del estatus constitucional de las lenguas. El castellano es reconocido como único idioma oficial a partir de la Constitución de 1945, si bien el mismo artículo también declara que "se reconocen el quechua y demás lenguas aborígenes como elementos de la cultura nacional” (Ecuador, 1945: art. 5), lo que hace de esta constitución la primera de todas las constituciones hispanoamericanas que menciona las lenguas indígenas. El castellano se queda como único idioma oficial también en las constituciones de 1946, 1967 y 1978 (codificada en 1984). A partir de la reforma constitucional de 1996, codificada en 1997, se declara un reconocimiento de las lenguas indígenas con limitación territorial, si bien no se explicita si se trata de un reconocimiento como lenguas oficiales: "El idioma oficial y de relación intercultural es el castellano. El quichua y las demás lenguas indígenas son reconocidas dentro de sus respectivas áreas de uso y forman parte de la cultura nacional” (Ecuador, 1997: art. 1). Solo a partir de la nueva Constitución de 1998 se explicita su "uso oficial para los pueblos indígenas" (Ecuador, 1998: art. 1), lo que se especifica en la última Constitución, de 2008, de la siguiente manera: "El castellano es el idioma oficial del Ecuador; el castellano, el kichwa y el shuar son idiomas oficiales de relación intercultural. Los demás idiomas ancestrales son de uso oficial para los pueblos indígenas en las zonas donde habitan y en los términos que fija la ley" (Ecuador, 2008: art. 2)15. El proyecto de ley al que alude el texto constitucional, Ley Orgánica de Derechos Lingüísticos de los Pueblos y Nacionalidades Indígenas, fue presentado a la Asamblea Nacional en 2012, pero aún no ha llegado ni siquiera al primer debate ${ }^{16}$. Por otra parte, en 2013 entró en vigor la Ley Orgánica de Comunicación, que establece normas de uso de las lenguas oficiales en los medios de comunicación, en especial la obligación de dedicar por lo menos un cinco por ciento de su programación diaria a "difundir contenidos que expresen y reflejen la cosmovisión, cultura, tradiciones, conocimientos y saberes de los pueblos y nacionalidades indígenas, afroecuatorianas y montubias", Ios cuales "tienen derecho a producir y difundir [estos contenidos] en su propia lengua" (Ecuador, 2013: art. 36).

15 Las reformas posteriores (la última es del 21 de diciembre de 2015) no han afectado este artículo.

16 Asamblea Nacional de la República del Ecuador, Leyes en proceso [http://www.asambleanacional. gob.ec/es/leyes-en-proceso?title=Ley+Org\%C3\%AInica+de+Derechos+Ling\%C3\%BCisticos+de+los +Pueblos+y+Nacionalidades+Ind\%C3\%ADgenas+\&field_proponente_value=henry+cuji\&field_comision_value=\&field_ano_tid=54, fecha de consulta: 29 de octubre de 2016]. 


\subsection{El Salvador}

El Salvador es otro país con un único idioma oficial, el castellano, declarado a partir de 1950 (El Salvador, 1950: art. 10), si bien a partir de la Constitución de 1982 se proclama también que "Ias lenguas autóctonas que se hablan en el territorio nacional forman parte del patrimonio cultural y serán objeto de preservación, difusión y respeto” (El Salvador, 1982: art. 62). El mismo compromiso se mantiene también en la Constitución actualmente vigente, que es del año siguiente, sin que las reformas posteriores (la última del 20 de junio de 2014) modificaran este artículo (El Salvador, 1983: art. 62). El Salvador no tiene una ley lingüística específica, por lo que la protección de sus lenguas indígenas está tratada dentro de la Ley Especial de Protección al Patrimonio Cultural de El Salvador, que, entre otros bienes culturales, incluye "la lengua náhuatl y las demás autóctonas, así como las tradiciones y costumbres” (El Salvador, 1993: art. 3). Además, el artículo 44 de esta ley está dedicado a la prohibición del cambio de topónimos autóctonos y otros nombres históricos y culturales.

\subsection{Guatemala}

A pesar de la fuerte presencia de las lenguas mayas en la sociedad guatemalteca, Guatemala es otro de los países con un único idioma oficial declarado, el español, si bien a partir de la Constitución de 1985 se declara también que las lenguas vernáculas "forman parte del patrimonio cultural de la Nación” (Guatemala, 1985: art. 143). Guatemala tiene una ley lingüística, Ley de Idiomas Nacionales (Ley 19/2003), que, sin embargo, repite que solo el español es el idioma oficial, pero a la vez declara que "el Estado reconoce, promueve y respeta los idiomas de los pueblos Mayas, Garífuna y Xinka” (Guatemala, 2003: art. 1), otorgándoles el estatus de idiomas nacionales a estas lenguas originarias.

En este contexto hay que mencionar el intento frustrado de la reforma constitucional de 1998, aprobada por el Congreso, pero rechazada en el referéndum de 1999, que cambiaba el artículo 143 sustancialmente:

Son idiomas oficiales del Estado: El Español para todo el territorio nacional y los idiomas indígenas que establezca la ley, fijando su ámbito de aplicación material de acuerdo a criterios técnicos, lingüísticos y territoriales.

El Estado reconoce, respeta y promueve los siguientes idiomas indígenas: Achi', Akateko, Awakateko, Chalchiteko, Ch'orti', Chuj, Itzá, Ixil, Popti', Kaqchikel, K’iche', Mam, Mopan, Poqoman, Poqomchi, Q’anjob’al, Q'eqchi', Sakapulteko, Sipakapense, Tekiteko, Tz'utujil, Uspanteko, Garifuna y Xinka (Guatemala, 1998: art. 143).

A pesar de que los idiomas indígenas no son declarados oficiales de iure, el ser reconocidos como idiomas nacionales les otorga cierto estatus y posibilidades de uso en el ámbito públi- 
co - educación, servicios de salud, contexto jurídico-. Como ilustración de la considerable tradición de su uso "oficial” puede servir el hecho de que ya la Constitución de 1985 se tradujo a varias lenguas mayas, como disponía uno de sus artículos transitorios: "En el curso del año de su vigencia, esta Constitución será ampliamente divulgada en lenguas Quiché, Mam, Cakchiquel y Kekchí” (Guatemala, 1985: art. trans. 18).

\subsection{Honduras}

Es uno de los países que otorgan el estatus de lengua oficial a una única lengua, el español, firmemente establecida a nivel constitucional a partir de 1957 (Honduras, 1957: art. 14). Entre los países hispanoamericanos tiene probablemente el documento legislativo sobre el uso oficial del español más antiguo (un acuerdo presidencial de 1882; Honduras, 1882: art. 3), y es uno de los pocos países en cuya Constitución declara como su deber la protección de la pureza del español y el incremento de su enseñanza (Honduras, 1982: art. 6)17. No tiene ninguna ley lingüística específica que trate el tema de las lenguas indígenas, pero hay cierto reconocimiento de ellas en la legislación que rige la educación: el Acuerdo Presidencial sobre la Educación Bilingüe Intercultural (1994) y la Ley Fundamental de Educación de 2011. No obstante, estos documentos se refieren solo al papel de las lenguas indígenas en el proceso educativo ${ }^{18}$.

\subsection{México}

México es uno de los países sin idioma oficial declarado de iure, y su ley lingüística, la Ley General de Derechos Lingüísticos de los Pueblos Indígenas, de 2003, se refiere tanto al español

17 Otros casos son El Salvador, cuya Constitución establece en relación con el español: "el gobierno está obligado a velar por su conservación y enseñanza” (El Salvador, 1983: art. 62), y Panamá, cuya Constitución declara: "el Estado velará por la defensa, difusión y pureza del idioma Español" (Panamá, 1972: art. 82). En la República Dominicana, el compromiso del Estado de proteger el español viene establecido por una ley (Dominicana, 2000: art. 2, inc. 6).

18 El Acuerdo Presidencial de 1994 señala, entre otros puntos: "d) La Educación Bilingüe Intercultural promoverá un bilingüismo de mantenimiento para rescatar y desarrollar las lenguas vernáculas", y "esta modalidad de Educación Bilingüe Intercultural de mantenimiento se establecerá para garantizar el uso fluido de la lengua vernácula y la oficial, en las formas oral y escrita; excluyéndose por tanto, el uso de la lengua vernácula en forma auxiliar y como mero puente para la castellanización" (Honduras, 1994: sección 1). La Ley Fundamental de Educación establece la incorporación de las lenguas indígenas en el sistema educativo: "El Currículo nacional debe incorporar en las diferentes modalidades del Sistema Nacional de Educación desde el nivel pre-básico, al menos: la enseñanza del idioma inglés, enseñanza en sus lenguas maternas a los pueblos indígenas y afrohondureños [...]" (Honduras, 2011: art. 60). 
como a las lenguas indígenas como lenguas nacionales y reconoce que todas estas lenguas "tienen la misma validez en su territorio, localización y contexto en que se hablen" (México, 2003: art. 4). Aun sin haber declarado técnicamente la oficialidad, les reconoce muchos usos propios de idiomas oficiales, y este uso tiene una limitación principalmente territorial, como se desprende del texto mencionado ${ }^{19}$. Esta ley es la más compleja en cuanto a qué lenguas indígenas se reconocen concretamente y dónde, ya que ha requerido la publicación oficial de un Catálogo de las Lenguas Indígenas Nacionales, elaborado por el Instituto Nacional de Lenguas Indígenas (INALI), en el Diario Oficial. Este documento de casi 250 páginas presenta una clasificación y ubicación pormenorizada de todas las lenguas mexicanas y llega a reconocer hasta 364 variantes lingüísticas (México, 2008)²0.

En cuanto al estatus constitucional de las lenguas indígenas en México, en 1992 se añadió al artículo 4 de la Constitución (México, 1917) un párrafo que, entre otros asuntos, declaraba: "La Nación mexicana tiene una composición pluricultural sustentada originalmente en sus pueblos indígenas. La ley protegerá y promoverá el desarrollo de sus lenguas, culturas, usos, costumbres, recursos y formas específicas de organización social [...]” (México, 1992). Este párrafo fue derogado en 2001 y, a la vez, fue reformado el artículo 2, cuya versión actual declara: "Esta Constitución reconoce y garantiza el derecho de los pueblos y las comunidades indígenas a la libre determinación y, en consecuencia, a la autonomía para: [...] IV. Preservar y enriquecer sus lenguas, conocimientos y todos los elementos que constituyan su cultura e identidad" (México, 2001).

\subsection{Nicaragua}

Nicaragua declaró el español como idioma oficial ya en la Constitución de 1939 (Nicaragua, 1939: art. 7) y lo mantuvo hasta el Estatuto Fundamental de 1979, que sustituyó la Constitu-

19 Esta ley a veces puede encontrarse interpretada como si hubiera otorgado a las lenguas indígenas y al español la misma validez en todo el territorio mexicano, pero esta no parece ser la intención del legislador. Si bien su en su territorio resulta algo ambiguo, se desprende del contexto que se refiere al territorio en el que se habla la lengua indígena en cuestión.

20 Según la interpretación del mismo INALI, a los efectos de la ley, "las variantes lingüísticas deben ser tratadas como lenguas" (México, 2008: 37, apart. 3.1.4). En este documento, en la parte de consideraciones, se menciona dos veces explícitamente el tema de la oficialidad de las lenguas indígenas como una demanda de los pueblos indígenas: "Que en los Foros de Consulta sobre Derechos Lingüísticos de los Pueblos Indígenas [...] se concluyó que en la Ley General de Derechos Lingüísticos de los Pueblos Indígenas se estableciera como obligación del Instituto Nacional de Lenguas Indígenas (INALI) realizar un catálogo de lenguas indígenas; que éstas deberían ser declaradas lenguas nacionales y oficiales en las regiones donde la población indígena fuera mayoritaria" (Méxic0, 2008: 31-32); "Que el reconocimiento gubernamental de las lenguas indígenas, considerando para ellas un estatus oficial, así como la equidad respecto del español, ha sido una demanda de los pueblos y comunidades indígenas de nuestro país" (México, 2008: 33). 
ción anterior, omitiendo este tema (Nicaragua, 1979; comp. Nicaragua, 1948, 1950, 1974). La declaración del idioma oficial, o, mejor dicho, de los idiomas oficiales, reaparece en la Constitución de 1987 y hace de Nicaragua uno de los primeros países en declarar la oficialidad de las lenguas indígenas ${ }^{21}$. Dicha oficialidad fue confirmada en una serie de leyes posteriores (28/1987, 162/1993, 757/2011), que, entre otros asuntos, llegan a identificar los idiomas oficiales: aparte del español se mencionan cinco idiomas indígenas (mískitu, sumu, garífuna, rama y, a partir de 2011, mayagna) y el creole (Nicaragua, 1993: art. 4; Nicaragua, 2011: art. 6). Esta oficialidad es limitada territorialmente: Ia Constitución alude a las comunidades de la Costa Atlántica (“Costa Caribe”, a partir de la reforma de 2014, Nicaragua, 1987b: art. 11) y las leyes posteriores ya hablan sobre su uso oficial en las Regiones Autónomas, hoy denominadas Región Autónoma de la Costa Caribe Norte y Región Autónoma de la Costa Caribe Sur.

\subsection{Panamá}

La Constitución panameña vigente declara como idioma oficial el español (Panamá, 1972: art. 7). Existe una ley lingüística, la Ley 88/2010, en la que "se reconocen las lenguas de los pueblos indígenas Ngäbe, Buglé, Kuna, Emberá, Wounaan, Naso Tjerdi y Bri Bri” (Panamá, 2010: art. 1), y, aunque esta ley a veces se interpreta como si se tratara de su reconocimiento como idiomas oficiales, literalmente no es así, ya que el tema de su oficialidad no se menciona y tampoco se dan detalles de qué consecuencias debe tener este reconocimiento a efectos públicos y legales. Esta ley se dedica más bien a dictar normas sobre la educación intercultural bilingüe $y$, en el anexo, establece alfabetos oficiales de las lenguas reconocidas. En lo que se refiere al uso oficial, garantiza más bien poco; por ejemplo, se garantiza el derecho de comunicarse con las autoridades competentes mediante intérpretes usando su propia lengua, "cuando no lo pueda hacer en español” (Panamá, 2010: art. 18). Curiosamente, este artículo aparece en el capítulo 4 "Uso de Vestidos Tradicionales".

\subsection{Paraguay}

La Constitución paraguaya de 1992 declara que "son idiomas oficiales el castellano y el guaraní", mientras que las lenguas indígenas junto con las de otras minorías se consideran patrimonio cultural y no tienen uso oficial (Paraguay, 1992: art. 140). En este contexto hay que resaltar un dato importante: aunque el guaraní es una lengua de origen amerindio, hoy en día no puede considerarse lengua indígena, siendo hablada por la mayoría de la población paraguaya.

21 "El español es el idioma oficial del Estado. Las lenguas de las Comunidades de la Costa Atlántica de Nicaragua también tendrán uso oficial en los casos que establezca la ley” (Nicaragua, 1987a: art. 11). 
La Constitución otorga a las dos lenguas mencionadas el mismo estatus cooficial, que viene matizado por la Ley de Lenguas, de 2010. Si bien en este caso no se trata de una limitación territorial, podemos encontrar algunas declaraciones que limitan el uso del guaraní y rompen el estatus legal equitativo de las dos lenguas, como, por ejemplo, que “las leyes de la República del Paraguay serán promulgadas en idioma castellano" (Paraguay, 2010: art. 14). Todos los usos oficiales del guaraní que requieren el uso de la escritura aparecen en la ley bajo la condición de "una vez establecidos el alfabeto y la gramática oficial del idioma guaraní" (Paraguay, 2010: art. 14, 15, 16, 18, 22, 23, 25), lo que aplaza el uso del guaraní para estos fines a un futuro desconocido actualmente 22.

\subsection{Perú}

Es el primer país que otorgó el reconocimiento como idioma oficial a una lengua indígena, el quechua, lo que se dio por el Decreto Ley 21.156, promulgado en 1975 (Perú, 1975: art. 1). El estatus oficial del quechua y el castellano es igual en este decreto, pero ya la Constitución de 1979 da un paso atrás y limita el uso oficial del quechua para "las zonas y la forma que la ley establece”; por otra parte, esta constitución otorga el mismo estatus al aymara, y las demás lenguas aborígenes son declaradas parte del patrimonio cultural (Perú, 1979: art. 83). La ley mencionada no se llega a formular, y en 1993 entra en vigencia una nueva constitución, que declara: "Son idiomas oficiales el castellano y, en las zonas donde predominen, también lo son el quechua, el aimara y las demás lenguas aborígenes, según la ley” (Perú, 1993: art. 48). La primera ley que lo concreta es del año 2003 (Perú, 2003), derogada por la siguiente ley lingüística de 2011, que establece: "Son idiomas oficiales, además del castellano, las lenguas originarias en los distritos, provincias o regiones en donde predominen, conforme a lo consignado en el Registro Nacional de Lenguas Originarias" (Perú, 2011: art. 9). Para los fines oficiales se utiliza actualmente la Base de Datos de Pueblos Indígenas u Originarios del Ministerio de Cultura, que en este momento reconoce 55 pueblos indígenas (y, por ende, lenguas, dos de las cuales se consideran extintas)23.

\subsection{Puerto Rico}

Es el único estado donde las dos lenguas oficiales, español e inglés, tienen el mismo estatus oficial, declarado por la ley 1/1993 (Puerto Rico, 1993: art. 1). Esta es la situación existente desde 1902 (Puerto Rico, 1902: sección 51), con una breve interrupción por la ley 4/1991, que declaró como único idioma oficial el español (Puerto Rico, 1991: art. 1).

22 Un análisis de esta ley se puede encontrar en Zajícová (2012).

23 Perú, Ministerio de Cultura, Base de Datos de Pueblos Indígenas u Originarios [http://bdpi.cultura. gob.pe/lista-de-pueblos-indigenas, fecha de consulta: 1 de noviembre de 2016]. 
El único artículo constitucional que se refiere a cuestiones lingüísticas es el relacionado con la elegibilidad a la Asamblea Legislativa: "Ninguna persona podrá ser miembro de la Asamblea Legislativa a menos que sepa leer y escribir cualquiera de los dos idiomas, español o inglés" (Puerto Rico, 1952: art. 3, sección 5). En septiembre de 2015 fue aprobado por el Senado puertorriqueño un proyecto de la ley que establece la jerarquía de estas dos lenguas con el reconocimiento del castellano como el primer idioma oficial. No obstante, esta ley aún no ha pasado por el proceso legislativo en la Cámara de Representantes²4.

\subsection{República Dominicana}

La República Dominicana tiene un único idioma oficial, la lengua castellana, declarada como tal ya por la ley 5136/1912 (Dominicana, 1912: art. 1); esto lo convierte en el primer país hispanoamericano en cuya legislación aparece el término idioma oficial. En la Constitución el español como idioma oficial fue incluido solo a partir de 2010 (Dominicana, 2010: art. 29; comp. la Constitución anterior, que aún no menciona este tema, Dominicana, 2002).

\subsection{Uruguay}

Uruguay es uno de los países con un único idioma oficial de facto, el español, no declarado ni por la Constitución (Uruguay, 1967) ni por la ley. El tema de otras lenguas está tratado solo en la ley de educación, que declara: “La educación lingüística tendrá como propósito [...] la consideración de las diferentes lenguas maternas existentes en el país (español del Uruguay, portugués del Uruguay, lengua de señas uruguaya) y la formación plurilingüe a través de la enseñanza de segundas lenguas y lenguas extranjeras" (Uruguay, 2008: art. 40, inc. 5).

\subsection{Venezuela}

Venezuela tenía un idioma declarado oficial, el castellano, definido a partir de la Constitución de 1961 (Venezuela, 1961: art. 6; comp. Venezuela, 1953). A partir de la Constitución de 1999, Venezuela declaró también el uso oficial de los idiomas indígenas "para los pueblos indígenas"

24 "Se declara el español como el primer idioma oficial y el inglés como el segundo idioma oficial del Gobierno del Estado Libre Asociado de Puerto Rico y serán utilizados en esa jerarquía en las Ramas Ejecutiva, Legislativa y Judicial del Estado Libre Asociado de Puerto Rico" (Puerto Rico, 2014: art. 1). Actualmente, está en trámite. El último paso se dio el 11 de marzo de 2016, cuando fue remitido a la Comisión de Calendarios de la Cámara [http://www.oslpr.org/legislatura/tl2013/tl_busca_avanzada.asp?rcs=, fecha de consulta: 29 de octubre de 2016]. 
y, a la vez, expuso que los idiomas indígenas deben ser "respetados en todo el territorio de la República” (Venezuela, 1999: art. 9)25. En consecuencia, tres de los 23 estados federales, Bolívar, Anzoátegui y Zulia, reflejaron la oficialidad de los idiomas indígenas en sus constituciones estatales (Venezuela, 2001: art. 9; 2002: art. 8; 2003: art. 9), mencionándose en la de Anzoátegui explícitamente el kariña. Después de la Ley Orgánica de Pueblos y Comunidades Indígenas de 2005, que reafirma que "Ios idiomas indígenas son de uso oficial para los pueblos indígenas" (Venezuela, 2005: art. 94) y especifica muchos contextos en los que el Estado garantiza su uso (en especial, arts. 96 y 97), en 2008 fue adoptada la Ley de Idiomas Indígenas, que enumera idiomas de 39 pueblos indígenas reconocidos por la ley, si bien declara que eso "no implica la negación de los derechos y garantías que tengan otros pueblos indígenas originarios no identificados en esta Ley” (Venezuela, 2008: art. 4). La ley venezolana es la única que no limita el uso oficial territorialmente, explicitando: "Los idiomas indígenas y el idioma castellano son los instrumentos de comunicación entre el Estado y los pueblos y comunidades indígenas, en cualquier escenario e instancia pública o privada en todo el territorio nacional” (art. 2). Así, el uso oficial es más bien limitado por sus usuarios, los pueblos y las comunidades indígenas. La ley venezolana también destaca por su continuo énfasis en que el uso y la preservación de una lengua no es solamente un derecho, sino también un deber de la comunidad indígena respectiva (v. en especial el art. 6): dado que las lenguas indígenas se consideran patrimonio cultural, sus usuarios tienen la obligación de preservarlas para toda la Nación y la Humanidad.

\section{Conclusiones}

La declaración de las lenguas indígenas como idiomas oficiales suele ser uno de los hitos en el amplio proceso para la emancipación de sus comunidades. Si bien es algo que por sí mismo no garantiza la preservación de estas lenguas, puede ayudar a los procesos sociales que, efectivamente, resultan favorables a su uso, mantenimiento y desarrollo.

En las últimas décadas, en todos los países hispanoamericanos con lenguas indígenas puede observarse un proceso similar que está conduciendo a una mayor promoción a nivel educacional, social y legal de sus idiomas autóctonos. En este sentido, varias naciones hispanoamericanas han optado también por declarar sus lenguas indígenas propias como cooficiales (en concreto, Bolivia, Colombia, Ecuador, Nicaragua, Perú, Venezuela y, en cierto sentido, también México y Paraguay). El auge de estos esfuerzos se produjo en la última década del siglo pasado y en la primera del siglo presente, aunque tenemos, por supuesto, casos que se adelantaron a esta cronología (el más notable es el caso de Perú, en 1975, seguido por el de Nicaragua, en 1987). No obstante, existen países donde estos esfuerzos aún no han dado un

25 La reforma constitucional de 2009 no ha afectado a este artículo (Venezuela, 2009: art. 9). 
resultado palpable (Chile, que solo tiene un proyecto de ley de 2014), o donde este proceso está inconcluso (Ecuador, que tiene declarada la oficialidad de los idiomas ancestrales a nivel constitucional, pero aún falta la ley que lo reglamente).

La variación que encontramos en la cronología de la legislación adoptada se da de una manera aún más pronunciada en su contenido. A pesar de que estamos ante una corriente general que va en la misma dirección, los resultados actuales son muy diferentes si comparamos el estatus constitucional de estas lenguas y las leyes lingüísticas vigentes, que van desde meras proclamaciones simbólicas hasta ambiciosos planteamientos. Hay países en que, aunque cuenten con una población indígena, su legislación prácticamente ignora la existencia de sus lenguas (Honduras); hay otros que solo las consideran patrimonio cultural (Costa Rica, El Salvador), mientras que otros países simplemente las "reconocen" (Panamá) o les otorgan el calificativo de idiomas o lenguas nacionales (Guatemala, México). Incluso entre la legislación de los países que las declaran oficiales existen muchas diferencias, como hemos observado páginas atrás: desde declaraciones más bien simbólicas (p. ej., en la legislación colombiana) hasta legislaciones mucho más exigentes (p. ej., la de Bolivia).

Cerramos con un dato comparativo que nos parece muy revelador: por un lado, tenemos Guatemala, con un único idioma oficial declarado y con más de tres millones de hablantes nativos de lenguas indígenas, lo que supone más de un cuarto de la población total; por el otro, Venezuela, con 39 idiomas indígenas reconocidos como oficiales y unos 300000 hablantes nativos, lo que supone apenas el uno por ciento de la población; es decir, el diferente estatus legal de las lenguas indígenas muchas veces no se corresponde con la diferente situación lingüística de los países y el diferente papel que estas lenguas cumplen en sus respectivas sociedades nacionales.

\section{TABLA 1}

Oficialidad de las lenguas indígenas por orden cronológico ${ }^{26}$

\begin{tabular}{llll} 
AÑo & PAís & NORMA & TEXTO \\
1975 & Perú & $\begin{array}{l}\text { Decreto Ley 21156, } \\
\text { art. I(derogado) }\end{array}$ & $\begin{array}{l}\text { "Reconócese el quechua, al igual que el castellano, como } \\
\text { lengua oficial de la República." }\end{array}$ \\
\hline
\end{tabular}

26 Esta tabla recoge solo aquellos artículos legislativos donde aparece explícita la oficialidad de las lenguas indígenas. Representan excepciones los casos de México, que no tiene declarado como oficial ningún idioma; Guatemala, que las declara idiomas nacionales; Colombia, cuya ley lingüística explicita el uso oficial de las lenguas nativas solo en un contexto muy concreto (la antroponimia y la toponimia); y Panamá, cuya ley lingüística declara que "reconoce" las lenguas indígenas sin especificar su estatus. Aun así, consideramos imprescindible incluir la información sobre esta legislación para tener el panorama completo. 


\begin{tabular}{|c|c|c|c|}
\hline 1979 & Perú & $\begin{array}{l}\text { Constitución, art. } \\
83 \text { (derogada) }\end{array}$ & $\begin{array}{l}\text { "El castellano es el idioma oficial de la República. También } \\
\text { son de uso oficial el quechua y el aymara en las zonas y la } \\
\text { forma que la ley establece. Las demás lenguas aborígenes } \\
\text { integran asimismo el patrimonio cultural de la Nación." }\end{array}$ \\
\hline 1987 & Nicaragua & Ley 28 , art. 5 & $\begin{array}{l}\text { "El español, idioma oficial del Estado, y las lenguas de las } \\
\text { Comunidades de las Costa Atlántica serán de uso oficial en } \\
\text { las Regiones Autónomas." }\end{array}$ \\
\hline 1991 & Colombia & Constitución, art. 10 & $\begin{array}{l}\text { "El castellano es el idioma oficial de Colombia. Las lenguas } \\
\text { y dialectos de los grupos étnicos son también oficiales en } \\
\text { sus territorios. [...]" }\end{array}$ \\
\hline 1992 & Paraguay & Constitución, art. 140 & $\begin{array}{l}\text { "El Paraguay es un país pluricultural y bilingüe. Son idio- } \\
\text { mas oficiales el castellano y el guaraní. La ley establecéá } \\
\text { las modalidades de utilización de uno y otro. Las lenguas } \\
\text { indígenas, y las de otras minorías, forman parte del patri- } \\
\text { monio cultural de la Nación." }\end{array}$ \\
\hline 1993 & Perú & Constitución, art. 48 & $\begin{array}{l}\text { "Son idiomas oficiales el castellano y, en las zonas donde } \\
\text { predominen, también lo son el quechua, el aimara y las de- } \\
\text { más lenguas aborígenes, según la ley." }\end{array}$ \\
\hline 1993 & Nicaragua & Ley 162, art. 1 & $\begin{array}{l}\text { "El español es el idioma oficial del Estado. Las lenguas de } \\
\text { las comunidades de la Costa Atlántica de Nicaragua serán } \\
\text { de uso oficial en las Regiones Autónomas, en los casos que } \\
\text { establezca la presente Ley." "Las Lenguas mískitu, creole, } \\
\text { sumu, garifona y rama son lenguas de uso oficial en las Re- } \\
\text { giones Autónomas de la Costa Atlántica." }\end{array}$ \\
\hline 1998 & Ecuador & Constitución, art. 1 & $\begin{array}{l}\text { "[...] El Estado respeta y estimula el desarrollo de todas las } \\
\text { lenguas de los ecuatorianos. El castellano es el idioma ofi- } \\
\text { cial. El quichua, el shuar y los demás idiomas ancestrales } \\
\text { son de uso oficial para los pueblos indígenas, en los térmi- } \\
\text { nos que fija la ley. [...]" }\end{array}$ \\
\hline 1999 & Venezuela & Constitución, art. 9 & $\begin{array}{l}\text { "El idioma oficial es el castellano. Los idiomas indígenas } \\
\text { también son de uso oficial para los pueblos indígenas y } \\
\text { deben ser respetados en todo el territorio de la República, } \\
\text { por constituir patrimonio cultural de la Nación y de la hu- } \\
\text { manidad." }\end{array}$ \\
\hline 2000 & Bolivia & $\begin{array}{l}\text { Decreto Supremo 25894, } \\
\text { art. } 1 \text { (derogado) }\end{array}$ & $\begin{array}{l}\text { "Se reconocen como idiomas oficiales Ias siguientes len- } \\
\text { guas indígenas: Aimara, Araona, Ayoreo, Baure, Besiro, Ca- } \\
\text { nichana, Cavineño, Cayubaba, Chácobo, Chimán, Ese ejja, } \\
\text { Guaraní, Guarasu?we (Pauserna), Guarayu, Itonama, Leco, } \\
\text { Machineri, Mojeño,[sic] trinitario, Mojeño-ignaciano, More, } \\
\text { Mosetén, Movima, Pacawara, Quechua, Reyesano, Sirionó, } \\
\text { Tacana, Tapieté, Toromona, Uru-chipaya, Weenhayek, Yami- } \\
\text { nawa, Yuki y Yuracaré." }\end{array}$ \\
\hline 2001 & Venezuela & $\begin{array}{l}\text { Constitución del } \\
\text { Estado Bolívar, art. } 9\end{array}$ & $\begin{array}{l}\text { "El idioma oficial en el Estado Bolívar es el castellano. Los } \\
\text { idiomas de los pueblos indígenas también son de uso ofi- } \\
\text { cial para sus respectivos pueblos y deben ser respetados } \\
\text { en todo el territorio del Estado, por constituir patrimonio } \\
\text { cultural de la Nación y de la humanidad. [...]" }\end{array}$ \\
\hline
\end{tabular}




\begin{tabular}{|c|c|c|c|}
\hline 2002 & Venezuela & $\begin{array}{l}\text { Constitución del Estado } \\
\text { Anzoátegui, art. } 8\end{array}$ & $\begin{array}{l}\text { "El idioma oficial es el Castellano. El Kariña y otros idiomas } \\
\text { indígenas son también oficiales para los pueblos indíge- } \\
\text { nas del Estado y deben ser respetados en todo el territorio } \\
\text { por constituir patrimonio cultural del Estado, la Nación y } \\
\text { la humanidad." }\end{array}$ \\
\hline 2003 & Venezuela & $\begin{array}{l}\text { Constitución del } \\
\text { Estado Zulia, art. } 9\end{array}$ & $\begin{array}{l}\text { "El idioma oficial es el castellano; pero en atención a la con- } \\
\text { dición multiétnica y pluricultural del Estado Zulia, también } \\
\text { son de uso oficial, en los pueblos indígenas que habitan su } \\
\text { territorio, los respectivos idiomas o lenguas, los cuales se } \\
\text { reconocen como Patrimonio Cultural de la Nación y de la } \\
\text { Humanidad, debiendo promoverse el respeto y conoci- } \\
\text { miento de los mismos. [...]" }\end{array}$ \\
\hline 2003 & México & $\begin{array}{l}\text { Ley General de } \\
\text { Derechos Lingüísticos } \\
\text { de los Pueblos } \\
\text { Indígenas, art. } 4\end{array}$ & $\begin{array}{l}\text { "Las lenguas indígenas que se reconozcan en los términos } \\
\text { de la presente Ley y el español son lenguas nacionales por } \\
\text { su origen histórico, y tienen la misma validez en su territo- } \\
\text { rio, localización y contexto en que se hablen." }\end{array}$ \\
\hline 2003 & $\begin{array}{l}\text { Guate- } \\
\text { mala }\end{array}$ & Decreto 19/2003, art. 1 & $\begin{array}{l}\text { "Idiomas nacionales. El idioma oficial de Guatemala es el } \\
\text { español. El Estado reconoce, promueve y respeta los idio- } \\
\text { mas de los pueblos Mayas, Garífuna y Xinka." }\end{array}$ \\
\hline 2003 & Perú & $\begin{array}{l}\text { Ley } 28106 \text {, art. } 1 \\
\text { (derogada) }\end{array}$ & $\begin{array}{l}\text { "La presente Ley tiene por objeto reconocer como idiomas } \\
\text { oficiales, en las zonas donde predominen, además del cas- } \\
\text { tellano, el quechua y el aimara, las lenguas aborígenes con- } \\
\text { sideradas en el Mapa del ‘Patrimonio Lingüístico y Cultural } \\
\text { del Perú, Familia Lingüísticas y Lenguas Peruanas»." }\end{array}$ \\
\hline 2004 & Argentina & $\begin{array}{l}\text { Ley } 5598 \text { (Provincia } \\
\text { de Corrientes), art. } 1\end{array}$ & $\begin{array}{l}\text { "ESTABLÉCESE el Guaraní como idioma oficial alternativo } \\
\text { de la Provincia de Corrientes." }\end{array}$ \\
\hline 2005 & Venezuela & $\begin{array}{l}\text { Ley Orgánica de } \\
\text { Pueblos y Comunidades } \\
\text { Indígenas, art. } 94\end{array}$ & $\begin{array}{l}\text { "Los idiomas indígenas son de uso oficial para los pueblos } \\
\text { indígenas y constituyen patrimonio cultural de la Nación } \\
\text { y de la humanidad, de conformidad con la Constitución de } \\
\text { la República Bolivariana de Venezuela y la presente Ley." }\end{array}$ \\
\hline 2008 & Venezuela & $\begin{array}{l}\text { Ley de Idiomas } \\
\text { Indígenas, art. } 4\end{array}$ & $\begin{array}{l}\text { "Son idiomas oficiales de la República Bolivariana de } \\
\text { Venezuela, el idioma castellano y los idiomas de los pue- } \\
\text { blos indígenas siguientes: kapón (akawayo), amorúa, añu, } \\
\text { aruako (lokono), ayamán, baniva (baniwa), baré (báre), barí, } \\
\text { chaima, kubeo, kumanagoto, e’ñepá, jodi (jodü), jivi (jiwi), } \\
\text { japreria, kari'ña, kurripako, kuiva, mako, makushi, ñengatú } \\
\text { (jeral), pemón (kamarakoto, arekuna, taurepan), chase (pia- } \\
\text { poko), puinave, pumé, sáliva, sanemá, sapé, timote, uruak } \\
\text { (arutani), wotjüja (piaroa), mopuoy (mapoyo), warekena, } \\
\text { warao, wayuu, yanomami, yavarana (yawarana), ye’kuana } \\
\text { (dhe’kuana) y yukpa. } \\
\text { La enunciación de los pueblos indígenas aquí señalados, } \\
\text { se establece en atención a la identidad propia y autodeno- } \\
\text { minación, y no implica la negación de los derechos y ga- } \\
\text { rantías que tengan otros pueblos indígenas originarios no } \\
\text { identificados en esta Ley." }\end{array}$ \\
\hline 2008 & Argentina & $\begin{array}{l}\text { Decreto } 3236 \text { (Provincia } \\
\text { de Chaco), art. } 1\end{array}$ & $\begin{array}{l}\text { "Téngase por lenguas oficiales de la Provincia del Chaco al } \\
\text { Qom, al Wichi y al Moqoit, lenguas de los Pueblos Indíge- } \\
\text { nas supervivientes de la Provincia." }\end{array}$ \\
\hline
\end{tabular}


2008 Ecuador Constitución, art. 2

2009 Bolivia Constitución, art. 5

2010 Colombia Ley 1381, art. 6

2010 Argentina Ley 6604 (Provincia de (haco), art. 1

2010 Panamá Ley 88, art. 6

2010 Paraguay Ley 4251, art. 3
"[...] El castellano es el idioma oficial del Ecuador; el casteIlano, el kichwa y el shuar son idiomas oficiales de relación intercultural. Los demás idiomas ancestrales son de uso oficial para los pueblos indígenas en las zonas donde habitan y en los términos que fija la ley. El Estado respetará y estimulará su conservación y uso."

"I. Son idiomas oficiales del Estado el castellano y todos los idiomas de las naciones y pueblos indígena originario campesinos, que son el aymara, araona, baure, bésiro, canichana, cavineńo, cayubaba, chácobo, chimán, ese ejja, guaraní, guarasu'we, guarayu, itonama, leco, machajuyaikallawaya, machineri, maropa, mojeńo-trinitario, mojeńoignaciano, moré, mosetén, movima, pacawara, puquina, quechua, sirionó, tacana, tapiete, toromona, uru-chipaya, weenhayek, yaminawa, yuki, yuracaré y zamuco.

II. El Gobierno plurinacional y los gobiernos departamentales deben utilizar al menos dos idiomas oficiales. Uno de ellos debe ser el castellano, y el otro se decidirá tomando en cuenta el uso, la conveniencia, las circunstancias, las necesidades y preferencias de la población en su totalidad o del territorio en cuestión. Los demás gobiernos autónomos deben utilizar los idiomas propios de su territorio, y uno de ellos debe ser el castellano."

"Los nombres y apellidos de personas provenientes de la lengua y de la tradición cultural usados por los hablantes de lenguas nativas, y más generalmente por los integrantes de pueblos y comunidades donde se hablen estas lenguas, podrán ser reconocidos para efectos públicos. Este uso será registrado por la autoridad oficial competente previa solicitud de los interesados. Igualmente los nombres de lugares geográficos usados tradicionalmente en su territorio por los integrantes de pueblos y comunidades donde se hablen lenguas nativas podrán ser registrados para efectos públicos. Este uso será cooficial con la toponimia en castellano cuando esta exista. [...]"

"Decláranse lenguas oficiales de la Provincia, además del Castellano-Español a las de los Pueblos Preexistentes Qom, Moqoit y Wichí, conforme las garantías establecidas por las Constituciones Nacional y Provincial (1957-1994) y normativas vigentes complementarias y concordantes."

"El Estado panameño reconoce la diversidad cultural, como un valor histórico y patrimonio de la humanidad, en todas sus manifestaciones, en consecuencia se reconocen las lenguas de los pueblos indígenas Ngäbe, Buglé, Kuna, Emberá, Wounaan, Naso Tjerdi y Bri Bri."

"De las lenguas oficiales. Las lenguas oficiales de la República tendrán vigencia y uso en los tres Poderes del Estado y en todas las instituciones públicas. El idioma guaraní deberá ser objeto de especial atención por parte del Estado, como signo de la identidad cultural de la nación, instrumento de cohesión nacional y medio de comunicación de la mayoría de la población paraguaya." 


\begin{tabular}{|c|c|c|c|}
\hline 2011 & Nicaragua & Ley 757, art. 6 & $\begin{array}{l}\text { "Uso de los idiomas oficiales. Las instituciones públicas y } \\
\text { privadas, deberán ofrecer y prestar sus servicios en las len- } \\
\text { guas de uso oficial (mískitu, creole, sumu, garífuna y rama) } \\
\text { y mayagna que utilizan los habitantes en sus respectivas } \\
\text { comunidades en combinación con el idioma español." }\end{array}$ \\
\hline 2011 & Perú & Ley 29735, art. 9 & $\begin{array}{l}\text { "Son idiomas oficiales, además del castellano, las lenguas } \\
\text { originarias en los distritos, provincias o regiones en donde } \\
\text { predominen, conforme a lo consignado en el Registro Na- } \\
\text { cional de Lenguas Originarias." }\end{array}$ \\
\hline 2012 & Bolivia & Ley 269 , art. 8 & $\begin{array}{l}\text { "Son idiomas oficiales del Estado, el castellano y todos } \\
\text { Ios idiomas de las naciones y pueblos indígena originario } \\
\text { campesinos, que son el Aymara, Araona, Baure, Bésiro, Ca- } \\
\text { nichana, Cavineño, Cayubaba, Chácobo, Chimane, Ese ejja, } \\
\text { Guaraní, Guarasu'we, Guarayu, Itonama, Leco, Machajuyai } \\
\text { kallawaya, Machineri, Maropa, Mojeño-Trinitario, Mojeño- } \\
\text { Ignaciano, Moré, Mosetén, Movima, Pacawara, Puquina, } \\
\text { Quechua, Sirionó, Tacana, Tapiete, Toromona, Uru-Chipaya, } \\
\text { Weenhayek, Yaminawa, Yuki, Yuracaré y Zamuco." }\end{array}$ \\
\hline 2013 & Chile & $\begin{array}{l}\text { Ordenanza municipal de } \\
\text { Galvarino de 07/08/2013 }\end{array}$ & $\begin{array}{l}\text { Se establece el mapuzungun lengua oficial junto al idioma } \\
\text { castellano en la comuna de Galvarino. }\end{array}$ \\
\hline 2014 & Chile & $\begin{array}{l}\text { Ordenanza municipal } \\
\text { de Padres Las Casas } \\
\text { de } 21 / 10 / 2014\end{array}$ & $\begin{array}{l}\text { Se declara el mapudungun como segunda lengua oficial en } \\
\text { la comuna de Padres Las Casas. }\end{array}$ \\
\hline
\end{tabular}

\section{Bibliografía citada 5.1. Fuentes legislativas}

Argentina, 1994 = Argentina, República de la: Constitución de la Nación Argentina, de 22 de agosto de 1994, Boletín Oficial de la República Argentina, n. ${ }^{\circ}$ 27.959, Suplemento, 23/08/1994 [https://www.boletinoficial.gob.ar/\#!DetalleNormativa/247236/null, fecha de consulta: 3 de noviembre de 2016].

Argentina, 2004 = Argentina, República de la, Provincia de Corrientes: Ley 5598/2004, de 28 de septiembre, Boletín Oficial de la Provincia de Corrientes, 22/10/2004 [http://sinca.cultura. gob.ar/sic/gestion/legislacion/Leyes/Corrientes_-_Ley_5598-04.txt, fecha de consulta: 13 de noviembre de 2015].

Argentina, 2008 = Argentina, República de la, Provincia de Chaco: Decreto 3236/2008, de 29 de agosto, Boletín Oficial, n. ${ }^{\circ} 8818,22 / 09 / 2008$, pág. 1 [http://portal1.chaco.gov.ar/uploads/boletin/boletin_8818.pdf, fecha de consulta: 3 de noviembre de 2016].

Argentina, 2009 = Argentina, República de la: Ley 26.522/2009, de Medios, de 10 de octubre, Boletín Oficial de la República Argentina, 19/10/2009 [https://www.boletinoficial.gob. ar/\#!DetalleNormativa/317910/null, fecha de consulta: 3 de noviembre de 2016]. 
Argentina, 2010 = Argentina, República de la, Provincia de Chaco: Ley 6604/2010, de 14 de julio, Boletín Oficial, n. ${ }^{\circ}$ 9092, 28/07/2010, págs. 3-4 [http://portal1.chaco.gov.ar/uploads/boletin/boletin_9092.pdf, fecha de consulta: 3 de noviembre de 2016].

BoLIVIA, 2000 = Bolivia, República de: Decreto Supremo 25.894/2000, de 11 de septiembre, Gaceta Oficial del Estado Plurinacional, n. ${ }^{\circ}$ 2243, 15/09/2000 [http://gacetaoficialdebolivia.gob.bo, fecha de consulta: 3 de noviembre de 2016].

BolıviA, 2009 = Bolivia, República de: Constitución Política del Estado, de 7 de febrero de 2009, Gaceta Oficial del Estado Plurinacional, 07/02/2009, Edición NCPE [http://gacetaoficialdebolivia.gob.bo/index.php/edicions/buscar, fecha de consulta: 3 de noviembre de 2016].

BolıviA, 2010 = Bolivia, Estado Plurinacional de: Ley 70/2010, de la Educación "Avelino Siñani Elizardo Pérez", de 20 de diciembre, Gaceta Oficial del Estado Plurinacional, 20/12/2010 [http:// gacetaoficialdebolivia.gob.bo, fecha de consulta: 3 de noviembre de 2016].

BoLIVIA, 2012 = Bolivia, Estado Plurinacional de: Ley 269/2012, General de Derechos y Políticas Lingüísticas, de 2 de agosto, Gaceta Oficial del Estado Plurinacional, 03/08/2012 [http://gacetaoficialdebolivia.gob.bo, fecha de consulta: 3 de noviembre de 2016].

ChILe, 1980 = Chile, República de: Constitución Política, de 11 de septiembre de 1980 [última versión de 16/11/2015], en Biblioteca del Congreso Nacional de Chile [https://www.leychile. cl/Navegar?idNorma=242302\&idVersion=, fecha de consulta: 3 de noviembre de 2016].

ChILE, 1993 = Chile, República de: Ley 19.253/1993, de 28 de septiembre [última versión de 25/03/2014], en Biblioteca del Congreso Nacional de Chile [http://www.leychile.cl/ $N ? i=30620 \& f=2014-03-25 \& p=$, fecha de consulta: 3 de noviembre de 2016].

CHILE, 2009 = Chile, República de, Ministerio de Educación, Subsecretaría de Educación: Decreto 280/2009, de 20 de julio, en Biblioteca del Congreso Nacional de Chile [http://www.leychile. $\mathrm{cl} / \mathrm{N} ? \mathrm{i}=1006477 \& \mathrm{f}=2009-09-25 \& \mathrm{p}=$, fecha de consulta: 3 de noviembre de 2016].

ChILE, 2014a = Chile, República de: Proyecto de Ley general de derechos lingüísticos de los pueblos indígenas de Chile, en Congreso de la República de Chile, Boletín, n. ${ }^{\circ}$ 9363-04, 20/05/2014 [http://www.senado.cl/appsenado/index.php?mo=tramitacion\&ac=getDocto\&iddocto=9777 \&tipodoc=mensaje_mocion, fecha de consulta: 4 de noviembre de 2016].

CHILE, 2014b = Chile, República de: Proyecto Ley general de derechos lingüísticos de los pueblos originarios de Chile, en Camara de Diputados De Chile, Boletín, n. 909424-17, 01/07/2014 [https:// www.camara.cl/pley/pdfpley.aspx?prmID=9636\&prmTIPO=INICIATIVA, fecha de consulta: 4 de noviembre de 2016].

Colombia, 1991 = Colombia, República de: Constitución Política, de 6 de julio de 1991, en Procuraduría General de la Nación [http://www.procuraduria.gov.co/guiamp/media/file/Macroproceso\%20Disciplinario/Constitucion_Politica_de_Colombia.htm, fecha de consulta: 4 de noviembre de 2016]. 
Colombia, 2010 = Colombia, República de: Ley 1381/2010, de 25 de enero, en International Labour Organization [http://ilo.org/dyn/natlex/docs/ELECTRONIC/83298/91870/F921480766/ COL83298.pdf, fecha de consulta: 3 de noviembre de 2016].

Costa Rica, 1949 = Costa Rica, República de: Constitución Política, de 7 de noviembre de 1949 [con reformas hasta 2003], en Biblioteca Virtual Miguel de Cervantes [http://www.cervantesvirtual.com/portales/constituciones_hispanoamericanas/obra/constitucion-politica-dela-republica-de-costa-rica-de-1949-incluye-las-reformas-hasta-2003/, fecha de consulta: 3 de noviembre de 2016].

CubA, 1940 = Cuba, República de: Constitución de la República, de 5 de julio de 1940, en Biblioteca Virtual Miguel de Cervantes [http://www.cervantesvirtual.com/portales/constituciones_hispanoamericanas/obra-visor-din/constitucion-del-5-de-julio-1940/html/ a162cb26-a174-4087-b2c8-02181083de04_2.html\#l_0_, fecha de consulta: 3 de noviembre de 2016].

CuBA, 1959 = Cuba, República de: Ley Fundamental, de 7 de febrero de 1959, en Biblioteca Virtual Miguel de Cervantes [http://www.cervantesvirtual.com/portales/constituciones_hispanoamericanas/obra-visor-din/constitucion-del-7-de-febrero-1959/html/ bb8efcc8-8de6-4b44-8be4-7alf4502bdc9_2.html\#I_0_,fecha de consulta: 3 de noviembre de 2016].

CubA, 1976 = Cuba, República de: Constitución de la República de Cuba, de 24 de febrero de 1976 [con reformas de 1992], en Portal Cuba [http://www.cuba.cu/gobierno/cuba.htm, fecha de consulta: 3 de noviembre de 2016].

DominICANA, 1912 = Dominicana, República: Ley 5136/1912, que declara idioma oficial de la República, la lengua castellana, de 18 de julio, Gaceta Oficial, n.ํ216, 24/07/1912, págs. 190191 [http://www.consultoria.gov.do/consulta/Default.aspx, fecha de consulta: 3 de noviembre de 2016].

Dominicana, 2000 = Dominicana, República: Ley 41-00/2000, que crea la Secretaría de Estado de Cultura, de 28 de junio, Gaceta Oficial, n. ${ }^{\circ}$ 10.050, 28/06/2000 [http://www.consultoria.gov.do/ consulta/Default.aspx, fecha de consulta: 3 de noviembre de 2016].

Dominicana, 2002 = Dominicana, República: Constitución, de 25 de julio de 2002, Gaceta Oficial, n. ${ }^{0}$ 10.240, 17/11/2003 [http://www.consultoria.gov.do/consulta/Default.aspx, fecha de consulta: 3 de noviembre de 2016].

Dominicana, 2010 = Dominicana, República: Constitución, de 26 de enero de 2010, Gaceta Oficial, n. ${ }^{\circ}$ 10.561, 26/01/2010 [http://www.consultoria.gov.do/consulta/Default.aspx, fecha de consulta: 3 de noviembre de 2016].

Ecuador, 1945 = Ecuador, República del: Constitución Política, de 6 de marzo de 1945, en Asamblea Constituyente del Ecuador [http://constituyente.asambleanacional.gob.ec/documentos/biblioteca/1945.pdf, fecha de consulta: 4 de noviembre de 2015]. 
Ecuador, 1946 = Ecuador, República del: Constitución Política, de 31 de diciembre de 1946, en Asamblea Constituyente del Ecuador [http://constituyente.asambleanacional.gob.ec/documentos/biblioteca/1946.pdf, fecha de consulta: 4 de noviembre de 2015].

Ecuador, 1967 = Ecuador, República del: Constitución Política, de 25 de mayo de 1967, en Asamblea Constituyente del Ecuador [http://constituyente.asambleanacional.gob.ec/documentos/biblioteca/1967.pdf, fecha de consulta: 4 de noviembre de 2015].

ECUADOR, 1984 = Ecuador, República del: Constitución Política: Constitución de 1978 codificada en 1984, de 16 de mayo de 1984, en Asamblea Constituyente del Ecuador [http://constituyente. asambleanacional.gob.ec/documentos/biblioteca/1978-codificada-en-1984.pdf, fecha de consulta: 4 de noviembre de 2015].

ECuAdor, 1996 = Ecuador, República del: Constitución Política: Constitución de 1979 reformada en 1996, de 29 de mayo de 1996, en Asamblea Constituyente del Ecuador [http://constituyente. asambleanacional.gob.ec/documentos/biblioteca/1979-reformada-en-1996.pdf, fecha de consulta: 4 de noviembre de 2015].

Ecuador, 1997 = Ecuador, República del: Constitución Política: Constitución de 1978 codificada en 1997, de 13 de febrero de 1997, en Asamblea Constituyente del Ecuador [http://constituyente.asambleanacional.gob.ec/documentos/biblioteca/1978-codificada-en-1997.pdf, fecha de consulta: 4 de noviembre de 2015].

Ecuador, 1998 = Ecuador, República del: Constitución Política, de 11 de agosto de 1998, en Asamblea Constituyente del Ecuador [http://constituyente.asambleanacional.gob.ec/documentos/biblioteca/1998.pdf, fecha de consulta: 4 de noviembre de 2015].

ECUADOR, 2008 = Ecuador, República del: Constitución, de 20 de octubre de 2008 [con reformas hasta 21/12/2015], en Asamblea Nacional del Ecuador [http://www.asambleanacional.gob.ec/ sites/default/files/private/asambleanacional/filesasambleanacionalnameuid-20/transparencia-2015/literal-a/a2/Const-Enmienda-2015.pdf, fecha de consulta: 3 de noviembre de 2016].

ECUADOR, 2012 = Ecuador, República del: Proyecto de Ley Orgánica de Derechos Lingüísticos de los Pueblos y Nacionalidades Indígenas, de 3 de mayo de 2012, en Asamblea Nacional, Leyes en proceso [http://documentacion.asambleanacional.gob.ec/alfresco/d/d/workspace/ SpacesStore/oed25f6g-56bd-4a17-812f-941d45dcb797/Ley\%20Org\%C3\%Alnica\%20de\%20 Derechos\%20Ling\%C3\%BCisticos\%20de\%20los\%20Pueblos\%20y\%20Nacionalidades\%20 Ind\%C3\%ADgenas\%20\%28Tr\%C3\%A1mite\%20No., fecha de consulta: 29 de octubre de 2016].

EcuAdor, 2013 = Ecuador, República del: Ley Orgánica de Comunicación, de 25 de junio de 2013, Registro Oficial, n. ${ }^{\circ}$ 22, Tercer suplemento, 25/06/2013 [http://www.asambleanacional.gob.ec/ es/system/files/ley_organica_comunicacion.pdf, fecha de consulta: 3 de noviembre de 2016].

El Salvador, 1950 = El Salvador, República de: Constitución Política, de 8 de septiembre de 1950, Decreto n. ${ }^{\circ}$ 14, en Biblioteca Virtual Miguel de Cervantes [http://www.cervantesvirtual.com/ portales/constituciones_hispanoamericanas/obra-visor-din/constitucion-politica-de-la-re- 
publica-de-el-salvador-de-1950/html/ab8ıebda-474e-4953-83a4-4e721ee6ab78_2.html\#l_0_, fecha de consulta: 3 de noviembre de 2016].

El Salvador, 1982 = El Salvador, República de: Constitución, de 26 de abril de 1982, Decreto n. ${ }^{\circ}$ 38, en Biblioteca Virtual Miguel de Cervantes [http://www.cervantesvirtual.com/portales/constituciones_ hispanoamericanas/obra-visor-din/constitucion-politica-de-la-republica-de-el-salvador-de-1982/ html/3469659f-276a-4ac1-93e3-867cefe4c06c_2.htm|\#l_0_fecha de consulta:3 de noviembre de 2016].

El Salvador, 1983 = El Salvador, República de: Constitución, de 15 de diciembre de 1983 [con reformas hasta 12/06/2014], Decreto n. ${ }^{\circ}$ 38, en Asamblea Legislativa de El Salvador, Centro de Documentación Legislativa [http://www.asamblea.gob.sv/eparlamento/indice-legislativo/buscador-de-documentos-legislativos/constitucion-de-la-republica, fecha de consulta: 3 de noviembre de 2016].

El SALVAdor, 1993 = El Salvador, República de: Decreto 513/1993, Ley especial de protección al patrimonio cultural de El Salvador, de 22 de abril, en Asamblea Legislativa de El Salvador, Centro de Documentación Legislativa [http://www.asamblea.gob.sv/eparlamento/indice-legislativo/ buscador-de-documentos-legislativos/ley-especial-de-proteccion-al-patrimonio-cultural-deel-salvador, fecha de consulta: 3 de noviembre de 2016].

Guatemala, 1985 = Guatemala, República de: Constitución Política, de 31 de mayo de 1985 [reformada por la Consulta Popular, Acuerdo Legislativo 18-93], en Congreso de la República de Guatemala [http://www.congreso.gob.gt/manager/images/1188FE6B-B453-3B8C-oDo0-549DA12F72CB.pdf, fecha de consulta: 3 de noviembre de 2016].

Guatemala, 1998 = Guatemala, República de: Proyecto de reforma constitucional del 16 de octubre de 1998, en Biblioteca Virtual Miguel de Cervantes [http://www.cervantesvirtual.com/ portales/constituciones_hispanoamericanas/obra/proyecto-de-reforma-constitucional-del16-de-octubre-de-1998, fecha de consulta: 3 de noviembre de 2016].

GuATEMALA, 2003 = Guatemala, República de: Decreto 19/2003, Ley de Idiomas Nacionales, de 7 de mayo, en CENADOJ-Centro Nacional de Análisis y Documentación Judicial [http://jurisprudencia.oj.gob.gt/frmprincipal.aspx, fecha de consulta: 3 de noviembre de 2016].

HonduRAs, 1882 = Honduras, República de: Acuerdo Presidencial, de 18 de diciembre de 1882, en Lenguas de Honduras [http://ccet-aecid.hn/diccionarios/normativas/\#oficial, fecha de consulta: 4 de noviembre de 2016].

Honduras, 1957 = Honduras, República de: Constitución Política, de 19 de diciembre de 1957 [con reformas hasta 05/02/1963], en Biblioteca Virtual Miguel de Cervantes [http://www.cervantesvirtual.com/portales/constituciones_hispanoamericanas/obra-visor-din/constitucionde-honduras-de-1957/html/1b511a0c-7533-4bdb-8672-041aa6acf1e4_2.html\#l_0_, fecha de consulta: 4 de noviembre de 2016].

Honduras, 1982 = Honduras, República de: Constitución Política, de 11 de enero 1982 [actualizada hasta 04/05/2005], en Congreso Nacional de Honduras [http://www.congresonacional. hn/dmdocuments/2014/CONSTITUCION-2005.pdf, fecha de consulta: 4 de noviembre de 2016]. 
Honduras, 1994 = Honduras, República de: Acuerdo Presidencial 0719-EP-94, de 3 de agosto de 1994, en Lenguas de Honduras [http://ccet-aecid.hn/diccionarios/normativas/\#intercultural, fecha de consulta: 4 de noviembre de 2016].

HondurAs, 2011 = Honduras, República de: Decreto 262/2011, Ley Fundamental de Educación, La Gaceta, n. ${ }^{\circ} 32.754,22 / 02 / 2012,1 \mathrm{~A}-15 \mathrm{~A}$, en Congreso Nacional de Honduras [http://www.congresonacional.hn/transparencia/images/leyes/2012/DecretoN02622011.pdf, fecha de consulta: 4 de noviembre de 2016].

Méxıco, 1917 = Estados Unidos Mexicanos: Constitución Política, de 5 de febrero de 1917 [con reformas hasta 29/01/2016], en Secretaría de Gobernación-Unidad General de Asuntos Juridicos, Orden Jurídico Nacional [http://www.ordenjuridico.gob.mx/Constitucion/cn16.pdf, fecha de consulta: 4 de noviembre de 2016].

Méxıco, 1992 = Estados Unidos Mexicanos: Decreto por el que se reforma el Artículo $4 .^{\circ}$ de la Constitución Política de los Estados Unidos Mexicanos, Diario Oficial de la Federación, 28/01/1992 [http://www.dof.gob.mx/nota_detalle.php?codigo=4646755\&fecha=28/01/1992, fecha de consulta: 4 de noviembre de 2016].

Méxıco, 2001 = Estados Unidos Mexicanos: Decreto por el que se aprueba el diverso por el que se adicionan un segundo y tercer párrafos al artículo 10., se reforma el artículo 20., se deroga el párrafo primero del artículo 40. [...], Diario Oficial de la Federación, 14/08/2001 [http://www. dof.gob.mx/nota_detalle.php?codigo=762221\&fecha=14/08/2001, fecha de consulta: 4 de noviembre de 2016].

Méxıco, 2003 = Estados Unidos Mexicanos: Ley General de Derechos Lingüísticos de los Pueblos Indígenas, Dia`rio Oficial de la Federación, 13/03/2003 [http://www.dof.gob.mx/nota_detalle. php?codigo=698625\&fecha=13/03/2003, fecha de consulta: 4 de noviembre de 2016] .

Méxıco, 2008 = Estados Unidos Mexicanos, Instituto Nacional de Lenguas Indígenas: Catálogo de las Lenguas Indigenas Nacionales: Variantes Lingüísticas de México con sus autodenominaciones y referencias geoestadísticas, Diario Oficial de la Federación, 14/01/2008 [http://www. dof.gob.mx/nota_to_doc.php?codnota=5028329, fecha de consulta: 4 de noviembre de 2016].

Nicaragua, 1939 = Nicaragua, República de: Constitución Política, de 22 de marzo de 1939, La Gaceta: Diario Oficial, n. ${ }^{\circ}$ 68, 23/03/1939, págs. 625-651 [http://digesto.asamblea.gob.ni/consultas/ util/pdf.php?type=rdd\&rdd=OtIHnXe8DUE\%3D, fecha de consulta: 4 de noviembre de 2016].

Nicaragua, 1948 = Nicaragua, República de: Constitución Política, de 21 de enero de 1948, La Gaceta: Diario Oficial, n. 16, 22/01/1948, págs. 129-155 [http://digesto.asamblea.gob.ni/consultas/util/pdf.php?type=rdd\&rdd=zaUKof3Aiq4\%3D, fecha de consulta: 4 de noviembre de 2016].

Nicaragua, 1950 = Nicaragua, República de: Constitución Política, de 1 de noviembre de 1950, La Gaceta: Diario Oficial, n. ${ }^{\circ}$ 235, 06/11/1950, págs. 2209-2243 [http://digesto.asamblea.gob. ni/consultas/util/pdf.php?type=rdd\&rdd=0XojYcgGEow\%3D, fecha de consulta: 4 de noviembre de 2016]. 
Nicaragua, 1974 = Nicaragua, República de: Constitución Política, de 3 de abril de 1974, La Gaceta: Diario Oficial, n. ${ }^{0}$ 89, 24/04/1974, págs. 817-847 [http://digesto.asamblea.gob.ni/consultas/ util/pdf.php?type=rdd\&rdd=WM4RGycJjWo\%3D, fecha de consulta: 4 de noviembre de 2016].

Nicaragua, 1979 = Nicaragua, República de: Estatuto Fundamental, de 20 de julio de 1979, La Gaceta: Diario Oficial, n. ${ }^{\circ}$ 1, 22/08/1979, págs. 1-4 [http://digesto.asamblea.gob.ni/consultas/util/ pdf.php?type=rdd\&rdd=0yB\%2FKeM7GBE\%3D, fecha de consulta: 4 de noviembre de 2016].

Nicaragua, 1987a = Nicaragua, República de: Constitución Política, de 9 de enero de 1987, La Gaceta: Diario Oficial, n. ${ }^{\circ}$ 5, 09/01/1987, págs. 33-64 [http://digesto.asamblea.gob.ni/consultas/ util/pdf.php?type=rdd\&rdd=VAGq\%2Frpgkec\%3D, fecha de consulta: 4 de noviembre de 2016].

Nicaragua, 1987b = Nicaragua, República de: Constitución Política [con reformas hasta 2014], de 9 de enero de 1987, La Gaceta: Diario Oficial, n. ${ }^{\circ}$ 32, 18/02/2014, págs. 1254-1284 [http://digesto. asamblea.gob.ni/consultas/util/pdf.php?type=rdd\&rdd=ND2SjevSidE\%3D, fecha de consulta: 4 de noviembre de 2016].

Nicaragua, 1987C = Nicaragua, República de: Ley 28/1987, de Estatuto de la autonomía de las regiones de la costa atlántica de Nicaragua, de 7 de septiembre, La Gaceta: Diario Oficial, n. ${ }^{\circ}$ 238, 30/10/1987, págs. 2833-2838 [http://digesto.asamblea.gob.ni/consultas/util/pdf.php?type =rdd\&rdd=TVmr7MO4A78\%3D, fecha de consulta: 4 de noviembre de 2016].

Nicaragua, 1993 = Nicaragua, República de: Ley 162/1993, de uso oficial de las lenguas de las comunidades de la Costa Atlántica de Nicaragua, de 22 de junio, La Gaceta: Diario Oficial, n. ${ }^{\circ}$ 132, 15/07/1996, págs. 2789-2791 [http://digesto.asamblea.gob.ni/consultas/util/pdf.php?type =rdd\&rdd=F4MrG28kOcc\%3D, fecha de consulta: 4 de noviembre de 2016].

Nicaragua, 2011 = Nicaragua, República de: Ley 757/2011, de trato digno y equitativo a pueblos indigenas y afro-descendientes, de 2 de marzo, La Gaceta: Diario Oficial, n. ${ }^{\circ}$ 96, 26/05/2011, págs. 29302932 [http://digesto.asamblea.gob.ni/consultas/util/pdf.php?type=rdd\&rdd=\%2Fs nagccwr4Y\%3D, fecha de consulta: 4 de noviembre de 2016].

OIT, 1989 = Organización Internacional de Trabajo: Indigenous and Tribal Peoples Convention, 1989 (No. 169): Convention concerning Indigenous and Tribal Peoples in Independent Countries, de 27 de junio de 1989 [http://www.ilo.org/dyn/normlex/en/f?p=1000:12100:0::NO::P12100_INSTRUMENT_ID,P12100_LANG_CODE:312314,es:NO, fecha de consulta: 4 de noviembre de 2016].

Panama, 1972 = Panamá, República de: Constitución Política, de 11 de octubre de 1972 [con reformas hasta 2004], Gaceta Oficial, n. ${ }^{\circ}$ 25.176, 15/11/2004, págs. 45-128 [http://200.46.254.138/ APPS/LEGISPAN/PDF_GACETAS/2000/2004/25176_2004.PDF, fecha de consulta: 4 de noviembre de 2016].

PANAmÁ, 2010 = Panamá, República de: Ley 88/2010, que reconoce las lenguas y los alfabetos de los pueblos indígenas de Panamá y dicta normas para la Educación Intercultural Bilingüe, de 22 de noviembre, Gaceta Oficial Digital, n. ${ }^{\circ}$ 26.669-A, 26/11/2010 [https://www.gacetaoficial. gob.pa/pdfTemp/26669_A/30623.pdf, fecha de consulta: 4 de noviembre de 2016]. 
Paraguay, 1967 = Paraguay, República del: Constitución de la República del Paraguay: Sancionada por la Convención Nacional Constituyente el 25 de Agosto de 1967 y promulgada por el Poder Ejecutivo en la misma fecha; Edición oficial, Asunción, Ministerio del Interior [http://www. cervantesvirtual.com/portales/constituciones_hispanoamericanas/obra-visor-din/constitucion-del-25-agosto-de-1967/html/2b52633b-6d61-431c-9e72-9a705b619eba_2.html\#l_0_fecha de consulta: 4 de noviembre de 2016].

Paraguay, 1992 = Paraguay, República del: Constitución, de 20 de junio de 1992 [https://web. archive.org/web/20160827165750/http://www.gacetaoficial.gov.py/datos/cons_es.pdf, fecha de consulta: 4 de noviembre de 2016].

Paraguay, 1998 = Paraguay, República del: Ley 1264/1998, General de Educación, de 26 de mayo [http://www.mec.gov.py/cms_v2/resoluciones/16-ley-12641998, fecha de consulta: 4 de noviembre de 2016].

Paraguay, 2010 = Paraguay, República del: Ley 4251/2010, de Lenguas, de 29 de diciembre, Gaceta Oficial de la República del Paraguay, n. ${ }^{\circ}$ 257, 31/12/2010, págs. 52-60 [http://www.gacetaoficial. gov.py/index/getDocumento/9346, fecha de consulta: 4 de noviembre de 2016].

Perú, 1975 = Perú, República del: Decreto Ley n. ${ }^{\circ}$ 21.156/1975, que reconoce el quechua como lengua oficial de la República, de 27 de mayo, en Archivo Digital de la Legislación del Perú [http://www.leyes.congreso.gob.pe/Documentos/Leyes/21156.pdf, fecha de consulta: 4 de noviembre de 2016].

Perú, 1979 = Perú, República del: Constitución para la República del Perú, de 12 de julio de 1979, en Archivo Digital de la Legislación del Perú [http://www.leyes.congreso.gob.pe/Documentos/ constituciones_ordenado/CONSTIT_1979/Cons1979_TEXTO_CORREGIDO.pdf, fecha de consulta: 1 de noviembre de 2015].

Perú, 1993 = Perú, República del: Constitución Política, de 29 de diciembre de 1993 [actualizado al 1 de mayo de 2013], en Archivo Digital de la Legislación del Perú [http://www.leyes. congreso.gob.pe/Documentos/constituciones_ordenado/CONSTIT_1993/Texto_actualizado_ CONS_1993.pdf, fecha de consulta: 4 de noviembre de 2016].

Perú, 2003 = Perú, República del: Ley n. ${ }^{\circ}$ 28.106/2003, de reconocimiento, preservación, fomento y difusión de las lenguas aborígenes, de 30 de octubre, El Peruano, 21/11/2003, pág. 255.568 [http://www. leyes.congreso.gob.pe/Documentos/Leyes/28106.pdf, fecha de consulta: 4 de noviembre de 2016].

PERú, 2011 = Perú, República del: Ley 29.735/2011, que regula el uso, preservación, desarrollo, recuperación, fomento y difusión de las lenguas originarias del Perú, de 2 de julio, El Peruano, 05/07/2011, págs. 445.799-445.801 [http://www.leyes.congreso.gob.pe/Documentos/Leyes/29735.pdf, fecha de consulta: 4 de noviembre de 2016].

Puerto Rico, 1902 = Puerto Rico: Ley de los Idiomas Oficiales, de 21 de febrero de 1902, en Jacques LeCLerc (ed.), Aménagement linguistique dans le monde [http://www.axl.cefan.ulaval.ca/ amsudant/portorico-loi-1902.htm, fecha de consulta: 4 de noviembre de 2016]. 
Puerto Rico, 1952 = Puerto Rico, Estado Libre Asociado de: Constitución, de 6 de febrero de 1952, en Biblioteca Virtual Miguel de Cervantes [http://www.cervantesvirtual.com/portales/ constituciones_hispanoamericanas/obra-visor-din/constitucion-del-estado-libre-asociadode-puerto-rico-de-1952/html/8ceoe6e2-3815-4a73-8866-4ccgecba835c_2.html\#I_0_fecha de consulta: 4 de noviembre de 2016].

Puerto Rico, 1991 = Puerto Rico, Estado Libre Asociado de: Ley 4/1991, de Idioma Oficial, de 5 de abril, en Jacques Leclerc (ed.), Aménagement linguistique dans le monde [http://www. axl.cefan.ulaval.ca/amsudant/portorico-loi-1991.htm, fecha de consulta: 4 de noviembre de 2016].

Puerto Rico, 1993 = Puerto Rico, Estado Libre Asociado de: Ley I/1993, de 28 de enero, en Portal Oficial de la Oficina de Servicios Legislativos de la Asamblea Legislativa de P.R. [http://www. oslpr.org/files/docs/\%7BCAE22D94-6EFA-4ADA-AFD6-21779908F437\%7D.pdf, fecha de consulta: 1 de noviembre de 2015].

Puerto Rico, 2014 = Puerto Rico, Estado Libre Asociado de, Senado de Puerto Rico: P. del S. 1177/2014, de 27 de agosto, en Portal Oficial de la Oficina de Servicios Legislativos de la Asamblea Legislativa de P.R. [http://www.oslpr.org/2013-2016/\%7B0C79C65F-CCEB-453E-B8D27C532EBD359D\%7D.doc, fecha de consulta: 29 de octubre de 2016].

URUGUAY, 1967 = Uruguay, República Oriental del: Constitución de la República: Constitución 1967 con las modificaciones plebiscitadas el 26 de noviembre de 1989, el 26 de noviembre de 1994, el 8 de diciembre de 1996 y el 31 de octubre de 2004, en República Oriental del Uruguay: Poder Legislativo [https://parlamento.gub.uy/documentosyleyes/constitucion, fecha de consulta: 4 de noviembre de 2016].

URUGUAY, 2008 = Uruguay, República Oriental del: Ley 18.437/2008, de 12 de diciembre, Diario Oficial, n. ${ }^{0}$ 27.654, 16/01/2009, págs. 247A-258A [http://www.impo.com.uy/copetes/pdf/20090116/ documentos.pdf, fecha de consulta: 4 de noviembre de 2016].

Venezuela, 1953 = Venezuela, República de: Constitución, de 15 de abril de 1953, en Tribunal SuPREMO DE JUSTICIA, Legislación [http://historico.tsj.gob.ve/legislacion/constitucion1953.pdf, fecha de consulta: 4 de noviembre de 2016].

Venezuela, 1961 = Venezuela, República de: Constitución, de 23 de enero de 1961, en Tribunal SuPREMO DE JUSTICIA, Legis/ación [http://historico.tsj.gob.ve/legislacion/constitucion1961.pdf, fecha de consulta: 4 de noviembre de 2016].

Venezuela, 1999 = Venezuela, República Bolivariana de: Constitución, de 20 de diciembre de 1999, Gaceta Oficial: de la República Bolivariana de Venezuela, n. ${ }^{0} 5453$ Extraordinario, 24/03/2000, págs. 1-45 [http://historico.tsj.gob.ve/legislacion/GO-24032000-5453.pdf, fecha de consulta: 4 de noviembre de 2016].

VenezUela, 2001 = Venezuela, República Bolivariana de, Estado Bolívar: Constitución del Estado Bolívar, de 2 de julio de 2001, en Georgetown University, Center for Latin American Studies (ed.): Politi- 
cal Database of the Americas, 1995-2006 [http://pdba.georgetown.edu/Security/citizensecurity/Venezuela/leyes/const-bolivar.doc, fecha de consulta: 4 de noviembre de 2016].

VenezUela, 2002 = Venezuela, República Bolivariana de, Estado Anzoátegui: Constitución del Estado Anzoátegui, de 30 de mayo de 2002, en Gaceta Oficial del Estado Anzoátegui, 73:551 (extraordinario), 01/07/2002, en Georgetown University, Center for Latin American Studies (ed.): Political Database of the Americas, 1995-2006 [http://pdba.georgetown.edu/Security/citizensecurity/ Venezuela/leyes/const-anzoategui.pdf, fecha de consulta: 4 de noviembre de 2016].

Venezuela, 2003 = Venezuela, República Bolivariana de, Estado Zulia: Constitución del Estado Zulia, de 5 de agosto de 2003, en Gobernación del Estado Zulia, 2012 [http://web.archive.org/ web/20120131150145/http://www.gobernaciondelzulia.gov.ve/lista2.asp?sec=1005, fecha de consulta: 4 de noviembre de 2016].

VenezUela, 2005 = Venezuela, República Bolivariana de: Ley Orgánica de Pueblos y Comunidades Indígenas, de 27 de diciembre de 2005, Gaceta Oficial: de la República Bolivariana de Venezuela, n. ${ }^{\circ}$ 38.344, 27/12/2005, págs. 343.651-343.664 [http://historico.tsj.gov.ve/gaceta/diciembre/271205/271205-38344-01.html, fecha de consulta: 4 de noviembre de 2016].

Venezuela, 2008 = Venezuela, República Bolivariana de: Ley de Idiomas Indígenas, de 28 de julio

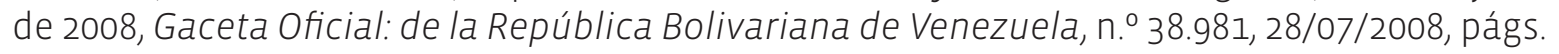
362.856-362.860 [http://historico.tsj.gov.ve/gaceta/julio/280708/280708-38981-2.html, fecha de consulta: 4 de noviembre de 2016].

Venezuela, 2009 = Venezuela, República Bolivariana de: Constitución, con la Enmienda No 1 aprobada por el Pueblo Soberano, mediante Referendo Constitucional, a los quince días del mes de febrero de dos mil nueve, de 19 de febrero de 2009, Gaceta Oficial: de la República Bolivariana de Venezuela, n. 5908 Extraordinario, 19/02/2009, págs. 1-48 [http://historico.tsj.gob. ve/legislacion/enmienda2009.pdf, fecha de consulta: 4 de noviembre de 2016].

\section{Bibliografía consultada}

Baldauf, Richard B., y Robert B. Kaplan, 2007: Language Planning and Policy in Latin America, 1: Ecuador, Mexico and Paraguay, Clevedon: Multilingual Matters.

Von Glelch, Utta, 2014: "Bolivia: multilingüismo intercultural en un Estado plurinacional” en Lenka Zajicová y Radim Zamec (eds.): Lengua y política en América Latina: perspectivas actuales, Olomouc: Univerzita Palackého v Olomouci, 177-196.

Herranz, Atanasio, 2000: Estado, sociedad y lenguaje: La política lingüística en Honduras, Tegucigalpa: Guaymuras.

López García, Ángel, 2012: “Modelos de planificación lingüística en Iberoamérica”, Revista Internacional de Lingüística Iberoamericana 10.1 (19), 11-27. 
Spolsky, Bernard, 2004: Language Policy, Cambridge: Cambridge University Press.

Süselbeck, Kirsten, Ulrike Mühlschlegel y Peter MAsson (eds.), 2008: Lengua, nación e identidad: La regulación del plurilingüismo en España y América Latina, Madrid/Frankfurt: Iberoamericana/ vervuert.

ZajicovA, Lenka, 2012: “La Ley de Lenguas paraguaya de 2010: Evolución y análisis”, Revista Internacional de Lingüística Iberoamericana 10.1 (19), 109-125.

Zimmermann, Klaus, 1999: Política del lenguaje y planificación para los pueblos amerindios: Ensayos de ecología lingüística, Madrid/Frankfurt: Iberoamericana/Vervuert. 